\title{
Microcrack propagation induced by dynamic infiltration of calcium-magnesium-alumino-silicate in columnar structures for thermal barrier coatings
}

\section{Shaochen Tseng}

National Taiwan University of Science and Technology

\section{Chingkong Chao}

National Taiwan University of Science and Technology

Weixu Zhang

Xi'an Jiaotong University

X.L. Fan ( $\nabla$ fanxueling@mail.xjtu.edu.cn )

\section{Research Article}

Keywords: Thermal barrier coating (TBC), columnar structure, CMAS infiltration, extended finite element method (XFEM)

Posted Date: June 17th, 2020

DOI: https://doi.org/10.21203/rs.3.rs-35895/v1

License: (c) (1) This work is licensed under a Creative Commons Attribution 4.0 International License. Read Full License

Version of Record: A version of this preprint was published at Journal of the Chinese Institute of Engineers on November 12th, 2020. See the published version at https://doi.org/10.1080/02533839.2020.1831968. 


\title{
[Title Page]
}

Microcrack propagation induced by dynamic infiltration of calcium-magnesiumalumino-silicate in columnar structures for thermal barrier coatings

\author{
Shaochen Tseng ${ }^{\mathrm{a}}$, Chingkong Chao ${ }^{\mathrm{a}}$, Weixu Zhang ${ }^{\mathrm{b}}$, Xueling Fan ${ }^{\mathrm{b}, *}$ \\ ${ }^{a}$ Department of Mechanical Engineering, National Taiwan University of Science and \\ Technology, R.O.C. \\ ${ }^{b}$ State Key Laboratory for Strength and Vibration of Mechanical Structures, School of \\ Aerospace Engineering, Xi'an Jiaotong University, Xi'an, China
}

\section{Correspondence information:}

Xueling Fan, State Key Laboratory of Strength and Vibration of Mechanical Structures school of Aerospace Engineering, Xi'an Jiatong University, No. 28 Xianning West Road, Xi'an, Shaanxi, 710049, P.R. China,

E-mail: fanxueling@mail.xjtu.edu.cn.

Tel. no.: +86-29-82667686, Fax no.: +86-29-82669044 


\title{
Microcrack propagation induced by dynamic infiltration of calcium-magnesium-alumino-silicate in columnar structures for thermal barrier coatings
}

\author{
Shaochen Tseng ${ }^{\mathrm{a}}$, Chingkong Chao ${ }^{\mathrm{a}}$, Weixu Zhang ${ }^{\mathrm{b}}$, Xueling Fan ${ }^{\mathrm{b}, *}$ \\ ${ }^{a}$ Department of Mechanical Engineering, National Taiwan University of Science and \\ Technology, R.O.C. \\ ${ }^{b}$ State Key Laboratory for Strength and Vibration of Mechanical Structures, School of \\ Aerospace Engineering, Xi'an Jiaotong University, Xi'an, China
}

\begin{abstract}
Columnar-structured thermal barrier coating systems (TBCs) possess a strain tolerant columnar microstructure wherein the gaps between the columns are filled with high-porosity oxides. At high temperatures, columnar-structured TBCs may be eroded via contact with a significant amount of calcium-magnesium-alumina-silicate (CMAS). A numerical model is proposed to estimate the temperature and stress fields of the microcracks induced by the CMAS infiltration. The energy release rate is evaluated to understand the influence of CMAS on the microcracks in the columnar microstructure. The effects of CMAS on the microcrack propagation are discussed in detail by using the extended finite element method. The results demonstrate that both the stress and energy release rate near the microcrack were found to dramatically increase when the CMAS reached the microcrack. Moreover, increasing the time of CMAS infiltration could destroy the thermal insulation provided by the top coat and considerably increase the energy release rate. The present analysis reveals that the vertical cracks are easily to initiate from the microstructure column and coalesce with adjacent horizontal and vertical pores, thereby resulting in premature failure of TBCs via delamination.
\end{abstract}

Keywords: Thermal barrier coating (TBC); columnar structure; CMAS infiltration; extended finite element method (XFEM).

* Corresponding authors

E-mail addresses: fanxueling@mail.xjtu.edu.cn 


\section{Introduction}

Thermal barrier coating systems (TBCs) have been extensively applied in the field of aerospace engineering for use in gas turbines and aero-engine components. These systems can prevent the failure of a turbine component upon undergoing high temperature oxidation processes for an extended period. TBCs mainly consists of a ceramic top coat (TC) that provides a layer of insulation, an underlying superalloy engine component in conjunction with two other layers between the substrate, and a bond coat (BC) layer, traditionally made of a NiCrAlY or NiCoCrAlY, and serve to reduce the oxidation and hot corrosion between the TC and substrate [1,2]. Upon thermal exposure, a thermally grown oxide (TGO) layer forms between the TC and BC layers. During the continuous high-temperature exposure experienced by operating gas-turbine engines, oxygen diffuses from the atmosphere into the internal layers, reacting with aluminum to form oxides $\left(\alpha-\mathrm{Al}_{2} \mathrm{O}_{3}\right)$ at the TGO/BC interface. The advanced material currently in use as the ceramic TC layer is approximately $7-8 \mathrm{wt} \%$ yttria stabilized zirconia (7YSZ). This material performs excellently as a result of its low thermal conductivity and high coefficient of thermal expansion [3]. YSZ is particularly resistant to hot corrosion because it possesses a relatively high melting point. The two major states arts of manufacturing for ceramic TC are laminar and columnar structure. The atmospheric plasma spray (APS), which is based on the former manufacturing method, exhibits the layer parallel to the interface. On the other hand, electron beam-physical vapor deposition (EB-PVD) is known as high strain tolerance owing to the specific columnar microstructure. Beside EB-PVD, suspension plasma spraying (SPS) and plasma sprayphysical vapor deposition (PS-PVD) are alternative methods for the columnar structure [4]. In this paper, we have focused only on the columnar structured coating, which possesses a strain-tolerant columnar grain microstructure and intercolumnar porosity. This columnar structure can be derivative to the TC layer of EB-PVD [5], SPS [6], and PS-PVD [7] TBCs. The voids between the columnar grains may not only provide strain tolerance, but also reduce the thermal conductivity of this layer, which is beneficial for its use in high temperature environments $[8,9]$.

The high temperature and harsh environmental conditions that gas turbines are operated in lead to the deposit of calcium-magnesium-alumino-silicate (CMAS) impurities, sand, runway debris, volcanic ash, air pollution, and fly ash into these turbines. A reasonable 
method of CMAS infiltration was described in earlier paper [10]. As a result of the eruption of the Eyjafjallajökull volcano in Iceland, aircraft engine manufacturers have paid a significant amount of attention to safety regulations regarding volcanic ash [11,12]. When CMAS adheres to the surface of the TC layer at high temperature, it rapidly penetrates into the gaps of the columnar microstructure. In brief, the CMAS may affect TBCs that are deposited by EB-PVD, PS-PVD, or APS, prompting a decrease in strain tolerance and the premature failure of the multilayered coating system [13]. Consequently, delamination and spallation would be induced via cracking. Therefore, it is essential to understand the failure mechanism of CMAS penetration into a TBCs. Several previous studies [14-17] have investigated CMAS-induced damage to TBCs. In a numerical study of CMAS, Chen [18] indicated that the thermal and elastic properties of CMAS greatly influence the energy release rate that may result in interfacial delamination. Su and Yi [19] concluded that a decrease of the in-plane modulus increases the strain energy release rate. The effect of interfacial crack geometric and material properties on the driving force in the coating system has been investigated by some researches [20-23]. The localized spallation of TBCs during of thermal exposure is been investigated by Zhang et al. [24]. The bending fracture behavior of freestanding coating has been studied by Mao et al. [25]. Jiang et al. [26,27] experimentally studied the influence of bending tests on TBCs. Recently, the transient thermal stress induced by CMAS has been studied by Chang et al. [28].

However, few researchers have investigated the crack propagation behavior induced by dynamic CMAS infiltration under thermal loading in the columnar-structured coating. Understanding the influence of dynamic CMAS infiltration on crack propagation can predict failure mechanism and service life, thereby providing the optimum design of the columnarstructured coating. Using finite element method, two major techniques are applied to simulate the interfacial crack dynamic behavior including the virtual crack closed technique (VCCT) [29] based upon energy release rates (J-integral) and the cohesive zone model (CZM) [30] based upon the traction-separation law. The path of crack propagation should be predefined in both of VCCT and CZM. This limitation is suitable for interfacial crack or simple model. However, it is difficult to determine the propagation path in complicated structures. The extended finite element method (XFEM) [31] as a useful technique can simulate the dynamic crack behavior. The propagation path is not necessary to define in simulation and complicated environment can be considered such as pores and inclusions. Recently, based on 
XFEM, Cai et al. [32] investigated the crack propagation induced by CMAS penetration during cooling stage. Nevertheless, the failure mechanism of the columnar-structured coating induced by CMAS has not yet been investigated owing to the complexities of dynamic CMAS infiltration and microstructure in the columnar-structured coating.

The two major objectives are studied in this article to understand the influence of CMAS dynamic infiltration on the microstructure of the columnar-structured TBCs. First, the temperature and stress fields around microcrack induced by CMAS dynamic infiltration are evaluated. The influence of CMAS properties (heat conductivity and thermal expansion coefficient), temperature gradient, and density of microcrack are investigated in this study. Second, the microcrack propagation behavior in YSZ column induced by dynamic CMAS infiltration is studied using the XFEM and the failure modes in columnar-structured coatings are discussed in detail.

\section{Numerical modeling}

The numerical analysis is performed using the commercial finite element program ABAQUS 6.14 [33]. The finite element models are constructed using a mesh with almost 45,000 elements, most of which are generalized plain strain elements. A mesh located near the microcrack tip and the YSZ/CMAS/high-porosity oxidation interface is applied to capture the singularity, and the mesh sensitivity is used to preserve the convergence of the calculations. The energy release rate is calculated based on the J-integral and the dynamic crack growth is calculated based on the XFEM. The transient temperature field during three thermal cycles is first simulated by a heat transfer procedure. To evaluate the corresponding thermal stress field, the temperature field is transported as a predefined field into the static procedure.

\subsection{Finite element model}

Based on experiment observation, several columnar microstructures in TC layer are shown in Fig. 1. The column structures deposited by EB-PVD, SPS, and PS-PVD TBCs are shown in Fig. (1a), Fig. (1b), and Fig. (1c), respectively. The columns of EB-PVD infiltrated by CMAS and crack propagation through several columns in infiltrated areas are shown in Fig. (1d). A plane-strain model of the microstructure of the columnar-structured coating is shown in Fig. 2. This unit-cell numerical model includes 11 YSZ columns, which are initially 
straight and parallel to one another, and possess a column width of $h$ and a gap width of $d$ between the columns. The column width used in this study is $\mathrm{h}=9 \mu \mathrm{m}$ and the high-porosity oxidation gap width is $\mathrm{d}=1 \mu \mathrm{m}$ because the porosity of the TC is about $10 \%$ [43-45]. The TGO layer is neglected in this study. $\mathrm{H}_{\mathrm{TC}}, \mathrm{H}_{\mathrm{BC}}$, and $\mathrm{H}_{\mathrm{SUB}}$ are the thicknesses of the TC, $\mathrm{BC}$, and substrate, respectively. $\mathrm{H}_{\mathrm{CMASO}}$ is the height of deposition on the surface of the TBC (i.e., on top of the TC), and $\mathrm{H}_{\mathrm{CMAS}}$ is the depth of the CMAS infiltration induced by the infiltration of CMAS into the column gaps of the columnar-structured TBCs. The depth of the substrate is set to $\mathrm{H}_{\mathrm{SUB}}=300 \mathrm{~mm}$, and the layer thicknesses are $\mathrm{H}_{\mathrm{TC}}=\mathrm{H}_{\mathrm{BC}}=100 \mu \mathrm{m}[4,26]$ and $\operatorname{HCMAS0}_{\mathrm{C}}=20 \mu \mathrm{m}$ [14]. To determine the influence of a crack by dynamic CMAS infiltration, a microcrack of length $2 \mathrm{a}$ with an angle of inclination $\theta$ with respect to the x-axis with a depth of $\mathrm{H}_{\mathrm{CRACK}}$, which is measured from the CMAS0/TC interface to the crack center, was preassigned in the YSZ \#6 column, as shown in Fig. 2.

\subsection{Material parameters}

In this study, the material properties of the TBC, including the Young's modulus, Poisson's ratio, coefficient of thermal expansion, the mass density, heat conductivity, and specific heat capacity demonstrate a linear elastic behavior. The material properties of all layers are listed in Table 1, including the hypothetical elastic and thermal characteristics of the highly porous oxides. The coefficient of thermal expansion and heat conductivity of the CMAS at high temperatures are listed in the following section. It should be noted that the selected temperature-dependent highly porous oxides are assumed to possess a relatively small Young's modulus and heat transfer coefficient.

\subsection{Thermal loading and boundary conditions}

The half-period geometric model used in this study is assumed to behave symmetrically on the left-edge and periodically on the right-edge of the system, as shown in Fig. 2. The left edge of this model is not permitted to move in the $x$-direction and the right edge may move freely. However, the parallel displacements of all the nodes on the right edge are assumed to be consistent with one another (via the multi-point constraint method). The top edge of the CMAS is free from any constraints. To ignore the bending moment of this model, the bottom edge is fixed in the vertical direction. The crack surface is assumed to be traction-free and thermally insulated from the heat flow. 
Fig. 3 shows the thermal loading profile. The temperature field of the entire TBCs is assumed to vary with time in every thermal cycle. The top of the CMAS and the bottom of the substrate are simultaneously and separately heated from $20{ }^{\circ} \mathrm{C}$ to $1350{ }^{\circ} \mathrm{C}$ for $\mathrm{T}_{\mathrm{CMAS}}$ and to $800{ }^{\circ} \mathrm{C}$ for $\mathrm{T}_{\mathrm{SuB}}$ over $300 \mathrm{sec}$. These high temperatures are maintained for $14400 \mathrm{sec}$ to allow for CMAS penetration. Then, the TBC is cooled to $20{ }^{\circ} \mathrm{C}$ over $300 \mathrm{~s}$. Note that During the holding time procedure, the temperature of the $\mathrm{TC}$ is always maintained below the melting point of CMAS $\left(\sim 1220^{\circ} \mathrm{C}\right)$. To consider the influence of heat transfer, the heating, holding, and cooling processes are used to address the transient thermal loading conditions for each thermal cycle. In the simulation, the stress-free is assumed as room temperature 20 ${ }^{\circ} \mathrm{C}$.

\subsection{CMAS penetration}

The gaps between the columns are initially filled with highly porous oxides. The subsequently deposited CMAS is drawn via capillary action into the open spaces between the columns. Naraparajuer et al. [34] experimentally determined the resistance towards CMAS infiltration using two real volcanic ashes and one synthetized CMAS powder. They provided an effective method to prevent infiltration by chemically reacting the molten glass to form a crystallized phase. Based on the experimental results presented in Ref. [34], the CMAS powder data is fitted to achieve a smooth curve, as shown in Fig. 4, to evaluate the infiltration depth as a function of time, $H_{C M A S}(t)$ :

$$
\mathrm{H}_{\text {CMAS }}(\mathrm{t})=70-30 \exp (-1.7 \mathrm{t})
$$

The infiltration rate, $I_{C M A S O}^{\&}$, is provided by:

$$
\mathrm{I}_{\mathrm{CMAS}}(\mathrm{t})=51 \exp (-1.7 \mathrm{t})
$$

The infiltration rate indicated in Eq. (2) satisfies the observed CMAS infiltration behavior in that the infiltration rate decreases due to an increase in viscous drag as the penetration depth into the TC layer increases. It should be emphasized that the value selected to represent the relationship between the infiltration depth and infiltration time is indicative of a specific temperature distribution and chemical reaction. The CMAS infiltration process operates via depvar (wherein numbers are specified for solution-dependent state variables) and user defined field (wherein the field variables are updated at material points for the user subroutine 
USDFLD) in ABAQUS. This enables us to transfer the material characteristics while undergoing high-porosity oxidation to simulate the CMAS dynamic infiltration process using the infiltration depth defined in Eq. (1). In general, the temperature of YSZ is almost higher than the melting point of CMAS $\left(\sim 1220^{\circ} \mathrm{C}\right)$ during the holding stage, while the temperature during cooling and heating stage would be smaller than the melting point. In simulation process, the critical temperature is chosen as $\sim 1220{ }^{\circ} \mathrm{C}$ and the CMAS infiltration is forced to terminate when local temperature around YSZ is less than $1220{ }^{\circ} \mathrm{C}$. In this study, some assumptions are made. First, the phase transformation is not considered during the cooling stage. In experiment observation, the volume expansion induced by CMAS infiltration experiences during cooling stage owing to the Tetragonal-Monoclinic transformation in Zirconia. Second, the region inside microcrack will not be infiltrated by CMAS because we only focus on the mechanical behavior of microcrack induced by the surrounding environment of CMAS infiltration in the columnar-structured TBCs.

\subsection{Microcrack propagation induced by CMAS penetration}

To study the dynamic damage process, VCCT and CZM methods are usually be implemented. However, the crack propagation path induced by the dynamic CMAS infiltration could not be predicted. Herein, XFEM is selected as modeling the microcrack propagation. The displacement in XFEM can be defined as [35]

$$
u_{X F E M}=\sum_{I \in N} N_{I}(x)\left[u_{I}+H(x) u_{a}+\sum_{\alpha} F_{\alpha}(x) \mathrm{u}_{b \alpha}\right]
$$

where $N_{I}(x)$ represents the standard shape function; $H(x)$ is called as Heaviside step function, which indicates that the displacement jump across the crack face; $F_{\alpha}(x)$ is the enrichment function of crack tip; $u_{I}$ is the degree of freedom of usual nodal, $u_{a}$ and $u_{b \alpha}$ are the degree of freedom of the enriched nodes. The enrichment elements are assigned in the region of the YSZ column \#6, where the pre-existing microcrack is assigned in this region. In conventional simulation analysis, the stress-strain curve is used to describe the mechanism behavior when the model is subjected to the boundary condition. However, a linear tractionseparation law [36] is applied to investigate the damage behavior of the material ahead of the crack tip. A damage model for XFEM is determined by a linear traction-separation as shown in Fig. 5 with D being the damage parameter which can be expressed as [37]: 


$$
D= \begin{cases}0, & \delta \leq \delta_{0} \\ \frac{\delta_{f}\left(\delta-\delta_{0}\right)}{\delta\left(\delta_{f}-\delta_{0}\right)}, & \delta_{0} \leq \delta \leq \delta_{f} \\ 1, & \delta \geq \delta_{f}\end{cases}
$$

where $\delta$ is the separation, $\delta_{0}$ is the critical opening separation and $\delta_{f}$ is the final failure separation. During the elastic behavior period, the linear curve with material stiffness $\mathrm{k}$ describes the mechanical behavior of the enriched region for the YSZ column \#6 as shown in Fig. 5. The point A represents the damage initiation point when the traction force reaches $T_{0}$. Damage initiation can be selected by either a critical principal stress or a critical separation criterion. In this analysis, the maximum principal stress criterion (MAXP) is selected as a damage initiation criterion of the YSZ column \#6, which can be expressed as

$$
f=\left\{\frac{\left\langle\sigma_{\operatorname{maxp}}\right\rangle}{\sigma_{\operatorname{maxp}}^{0}}\right\}
$$

the damage initiation occurs when $\mathrm{f}$ is greater or equal to one, where $\sigma_{\operatorname{maxp}}^{0}$ is the critical value of maximum principal stress. $\langle\mathrm{g}\rangle$, which is called as the Macaulay bracket, indicates that the crack would not initiate under compressive stress. After passing the point A, the material of the enriched region would be considered by fracture behavior. From the point A to point $\mathrm{C}$, the traction force of materials will be reduced when the crack plane begins to separate under degradation process. If unloading occurs at the point $\mathrm{B}$, the material stiffness transfers to (1$\mathrm{D}) \mathrm{k}$ for the next loading process. Final failure occurs at the point $\mathrm{C}$ which indicates that the strain energy release rate is larger than the critical fracture toughness $G_{c}$. The critical strain energy release rate can be calculated as the area under the traction-separation graph as follows

$$
G_{c}=\frac{1}{2} T_{0} \delta_{f}
$$

Generally, the critical strength is influenced by the material characteristic (material properties, microstructure and spraying method). In previous investigations [38], the critical 
strength ranged from 30 to $200 \mathrm{MPa}$. In the present work, the critical strength $\left(\sigma_{\operatorname{maxp}}^{0}\right)$ is selected as $120 \mathrm{MPa}$ and the fracture toughness $\left(G_{c}\right)$ is assumed as $20 \mathrm{~J} / \mathrm{m}^{2}$ [39].

\section{Results and discussions}

\subsection{Temperature field}

During the high temperature holding stage, the temperature distribution between the 800 ${ }^{\circ} \mathrm{C}$ and $1350{ }^{\circ} \mathrm{C}$ materials is shown in Fig. 6. Note that the thermal conductivity of the TC layer $\left(1.05 \mathrm{~W} \mathrm{~m}^{-1} \mathrm{~K}^{-1}\right)$ is the lowest amongst all layers, and the TC layer provides a total of almost $150{ }^{\circ} \mathrm{C}$ of thermal insulation. Fig. 7 plots the heat insulation capacity in the TC layer with different CMAS thermal conductivities at a constant high-temperature (ignoring the heating and cooling stages). Note that the heat insulation capacity shown in Fig. 7 represents the temperature difference $\Delta T$ between the top (CMAS0/TC) and bottom (TC/BC) TC interfaces. It is shown that a higher CMAS thermal conductivity with more severe CMAS infiltration reduces the insulation capability of the TC layer via the penetration of the highporosity oxides by CMAS, as expected [44]. A crack 4- $\mu \mathrm{m}$ in length that is embedded in column \#6 with $\mathrm{H}_{\mathrm{CRACK}}=60 \mu \mathrm{m}$ was considered. The temperature and heat flux contours around the microcrack induced using different angles of inclination during the hightemperature process are depicted in Fig. 8. There exists a large temperature gradient near the crack tip with an inclined angle of $\theta=0^{\circ}$, as shown in Fig. 8(a), and the temperature distribution was not influenced by a perpendicular crack, as shown in Fig. 8(d). These figures can confirm that the CMAS still appears as fluid state because the local temperature around microcrack is almost $1260{ }^{\circ} \mathrm{C}$. Fig. 9 shows the normalized heat flux around the tip-B of the crack for different inclination angles during CMAS infiltration. The magnitudes of the heat flux are normalized using a reference value obtained when using an inclination angle of $\theta=0^{\circ}$. As expected, the magnitude of the heat flux decreases as the inclination angle is increased. In addition, the magnitude of the heat flux of a perpendicular crack is almost the same as that experienced without cracking because a perpendicular crack does not block the flow of heat. Fig. 10 shows the heat flux distribution of TC layer for different thermal cycles. The zone I represents the CMAS penetrated zone and zone II represents the CMAS nonpenetrated zone. The CMAS penetration depth gradually increases with the infiltration time. 
In conclusion, the temperature and heat flux fields are considerably affected by both the inclination angles of the microcracks and the infiltration depth of CMAS.

\section{2. $\quad$ Stress field}

The stresses affected by the infiltration of CMAS may be classified into three types [27]. Type I occurs when the microcrack $\left(\mathrm{H}_{\mathrm{CRACK}}=60 \mu \mathrm{m}\right)$ is far from the CMAS during the first thermal cycle $\left(\mathrm{H}_{\mathrm{CMAS}}=40-55 \mu \mathrm{m}\right)$, wherein the stresses are relatively small and become stable because the stress field around the microcrack is not influenced by the CMAS. Type II occurs when the CMAS begins to reach the microcrack during the second thermal cycle $\left(\mathrm{H}_{\mathrm{CMAS}}=55-63 \mu \mathrm{m}\right)$, and the stresses gradually increase because of changes in the local environment surrounding the microcrack as a result of the CMAS. Here, the infiltrated molten CMAS would solidify and occupy the inner space between the columns of the columnar-structured TBCs, resulting in a large degradation of the strain tolerance and delamination as a result of the microcrack propagation. In type III, the microcrack $\left(\mathrm{H}_{\mathrm{CRACK}}=\right.$ $60 \mu \mathrm{m})$ is already covered by the CMAS during the third thermal cycle $\left(\mathrm{H}_{\mathrm{CMAS}}=63-67 \mu \mathrm{m}\right)$ and the stresses are stable and maintained at a high value. Fig. 11 shows the maximum principal stress distribution for different thermal cycles when a microcrack is embedded in column \#6 $\left(\mathrm{H}_{\mathrm{CRACK}}=60 \mu \mathrm{m}\right)$ and the inclination angle of the microcrack is $60^{\circ}$. It is interesting to see that the stress field of a microcrack has not been influenced by CMAS infiltration at $\mathrm{t}=9000 \mathrm{~s}$ (type I) during the first thermal cycle (Fig. (11a)). When the infiltration time increases up to $t=24000 \mathrm{~s}$ (type II) during the second thermal cycle, the CMAS starts to reach the microcrack leading to a higher local stress around the tip-B as shown in Fig. 11(b). As the infiltration time increases up to $t=39000 \mathrm{~s}$ (type III) during the third thermal cycle, both the two crack tips of microcrack are covered by CMAS infiltration resulting in a significant increase in local stress around two crack tips as shown in Fig. (11c).

The fracture behavior of the microcrack upon CMAS infiltration is also analyzed. Both the open-mode stress, $\sigma_{T T}$ (tensile stress normal to the plane of the crack, measured in MPa), and the sliding-mode stress, $\sigma_{N T}$ (shear stress acting parallel to the plane of the crack, measured in $\mathrm{MPa}$ ), around the microcrack tip are investigated upon CMAS infiltration. These stresses around the microcrack tip versus the CMAS infiltration at different crack inclination angles are depicted in Fig. 12 and Fig. 13, respectively, where a microcrack is embedded in column \#6 $\left(\mathrm{H}_{\mathrm{CRACK}}=60 \mu \mathrm{m}\right)$. As expected, the stresses increase during heating and decrease 
during cooling. The stresses experience a dramatically turbulent phenomenon when the CMAS begins to reach the microcrack during the second thermal cycle. Fig. 12 shows that the microcrack seems to behave as an open-mode fracture when the inclination angle of the microcrack is 30,60 or $90^{\circ}$. Fig. 13 shows that the microcrack behaves as a sliding-mode fracture when the inclination angle of the microcrack is either 30 or $60^{\circ}$. It is interesting to note that the magnitude of the sliding-mode stress around tip-A at $\theta=30^{\circ}$ is larger than that at $\theta=60^{\circ}$ during the second thermal cycle in Fig. 13(a). However, the magnitude of the sliding-mode stress around tip-B at $\theta=30^{\circ}$ is smaller than that at $\theta=60^{\circ}$ during the second thermal cycle, as shown in Fig. 13(b), and this occurs due to differing distances between the crack tip and CMAS. Fig. 13(b) shows that the sliding-mode stress around tip-B at an inclination angle of $60^{\circ}$ is bigger than that at $30^{\circ}$. This is because the distance between tip-B and the CMAS at $60^{\circ}$ is smaller than that between tip-B and the CMAS at $30^{\circ}$. Conversely, the distance between tip-A and the CMAS at $60^{\circ}$ is larger than that between tip-A and the CMAS at $30^{\circ}$. Therefore, the CMAS would reach tip-B at a 60-degree inclination angle more quickly than at a 30-degree inclination angle. In addition, the open-mode stress and the sliding-mode stress of a horizontal crack are rarely influenced by the infiltration of CMAS.

Next, the energy release rate is evaluated under the dynamic CMAS infiltration during the thermal loading. All energy release rate results presented in this section are normalized using a reference value, GMAX. The energy release rate at different inclination angles in relation to the infiltration time is presented in Fig. 14. As mentioned above, both the openmode stress and the sliding-mode stress dramatically increase as the CMAS reaches the microcrack. Consequently, the energy release rate increases rapidly upon the second thermal cycle, as shown in Figs. 14-17. In addition, the energy release rate at both tip-A and tip-B monotonically increases as the inclination angle increases.

In the following discussion, the inclination angle of the microcrack is fixed at $60^{\circ}$. The influence of the thermal expansion coefficient of the CMAS on the energy release rate at high temperatures during CMAS infiltration is shown in Fig. 15. A decrease in the thermal expansion coefficient of the CMAS at high temperatures during thermal cycling results in a notable increase in the driving force for propagation of the microcrack. Crack delamination may then occur as a result of the significant thermal misfit stress. The larger the mismatch of the thermal expansion between the CMAS and TC layer, the higher the magnitude of the 
energy release rate that will be accumulated in the YSZ column layer, thereby resulting in microcrack propagation. The influence of the crack height on the energy release rate is shown in Fig. 16. The time at which the energy release rate dramatically increases will differ between different crack heights. For example, the time at which the energy release rate dramatically increases in the first $\left(\mathrm{H}_{\mathrm{CMAS}}=40-55 \mu \mathrm{m}\right)$, second $\left(\mathrm{H}_{\mathrm{CMAS}}=55-63 \mu \mathrm{m}\right)$, and third

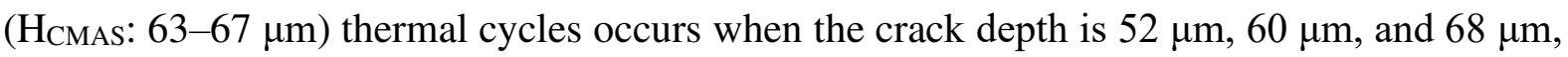
respectively. This can be attributed to the fact that the energy release rate dramatically increases as the CMAS reaches the microcrack. It is interesting to note that the energy release rate of tip-B is obviously larger than that of tip-A if the depth of the microcrack is $68 \mu \mathrm{m}$ during the third thermal cycle. In reality, the CMAS $\left(\mathrm{H}_{\mathrm{CMAS}}=67 \mu \mathrm{m}\right)$ reaches tip-B $\left(\mathrm{H}_{\mathrm{CRACK}}\right.$ в $=66.3 \mu \mathrm{m})$ while it does not reach tip-A $\left(\mathrm{H}_{\text {CRACK-A }}=69.7 \mu \mathrm{m}\right)$. Therefore, the impact of CMAS at tip-B is greater than that at tip-A when the inclination angle of the microcrack is fixed at $60^{\circ}$.

Finally, in order to consider multiple microcracks in the YSZ columns, the effect of the microcrack density on the energy release rate is depicted in Fig. 17. Three different cases were considered for different amounts of microcracks $\left(\mathrm{N}_{\mathrm{CRACK}}\right)$ : $\mathrm{N}_{\mathrm{CRACK}}=1$ for a crack located at column \#6, $\mathrm{N}_{\mathrm{CRACK}}=3$ for cracks located at columns \#3, \#6, and \#9, and $\mathrm{N}_{\mathrm{CRACK}}=$ 5 for cracks located at columns \#2, \#4 \#6, \#8, and \#10. The numerical results indicate that the energy release rate of $\mathrm{N}_{\mathrm{CRACK}}=1$ is larger than that of both $\mathrm{N}_{\mathrm{CRACK}}=3$ and $\mathrm{N}_{\mathrm{CRACK}}=5$. This is because the energy release rate is concentrated at the tip of a single microcrack in this case. The possibility of microcrack propagation can therefore be greatly reduced by increasing the density of the cracks, which is consistent with the findings of previous studies for the density of the cracks $[15,16]$.

\subsection{Microcrack propagation induced by CMAS infiltration}

There exists a great possibility for the microcrack propagation induced by dynamic CMAS infiltration. In this section, the microcrack propagation induced by dynamic CAMS infiltration is investigated using XFEM. In the following discussion, the microcrack is embedded in column \#6 $\left(\mathrm{H}_{\mathrm{CRACK}}=60 \mu \mathrm{m}\right)$, the inclination angle of the microcrack is either $60^{\circ}$ or $30^{\circ}$ and the enrichment elements are assigned in column \#6 of YSZ.

Fig. 18 indicates the normalized crack growth under dynamic CMAS infiltration while Fig. 19 displays the process of microcrack propagation with time. When the inclination angle 
of the microcrack is $60^{\circ}$, the microcrack in column \#6 of YSZ is unable to grow, herein the crack growth is almost zero during the heating and holding stage in the first thermal cycle as displayed in Fig. 18(a). Note that the normalized crack growth is defined as the crack growth divided by the height of $\mathrm{TC}\left(\mathrm{H}_{\mathrm{TC}}\right)$. It can be seen that the stress around the microcrack still maintains a small value since CMAS did not reach the microcrack as shown in Fig. 19 (a). During the cooling stage in the first thermal cycle, the tip-B starts to propagate when the maximum principal stress and fracture toughness reach their critical values. Fig. 19(b) displays that the microcrack starts to propagate around $14800 \mathrm{~s}$ (cooling stage during the first thermal cycle) at tip-B. As mentioned in the previous section, tip-B will propagate first since the distance between tip-B and the CMAS at $60^{\circ}$ is smaller than the distance between tip-A and the CMAS at $60^{\circ}$. When the infiltration time increases up to $18000 \mathrm{~s}$ (holding stage during the second thermal cycle), the tip-A also starts to propagate because both the maximum principal stress and fracture toughness exceed their critical values as shown in Fig. 19(c). Both the tip-A and tip-B continue to propagate as the infiltration time increases up to $29650 \mathrm{~s}$ (holding stage during the second thermal cycle) as shown in Fig. 19(d). The crack growth result shows that the crack propagates slowly during the holding stage in the second thermal cycle as indicated in Fig. 18(a). Subsequently, the column structure encounters a severely damaged pattern during the cooling stage. At this moment, the crack starts to propagate quickly during the cooling stage in the second thermal cycle owing to a large thermal mismatch between CMAS and column structure. As shown in Fig. 19(e), a significant increase in thermal mismatch accelerates the driving force to microcrack propagation along the YSZ column around $29900 \mathrm{~s}$ (cooling stage in the second cycle). As we mentioned above, the large degradation of the strain tolerance and delamination occurs in this situation. Fig. 18(a) shows that the crack growth experiences a big jump in the black flame at this moment. As shown in Fig. 19(f), the tip-A slowly propagates downward when the CMAS infiltration rate decreases owing to an increase in viscous drag as the penetration depth increases around $44900 \mathrm{~s}$ (cooling stage in the third thermal cycle). It could speculate that the tip-A will propagate downward and extend to the interface YSZ/BC when the YSZ is entirely infiltrated by CMAS. The crack propagation pattern of the $30^{\circ}$ inclination angle of the microcrack is provided in Fig. 19(g). This result is consistent with the above finding of the energy release rate analysis indicating that the energy release rate value of $30^{\circ}$ is much smaller than the energy release rate value of $60^{\circ}$ as shown in Fig. 14. Referring to Fig. 18, the normalized crack growth of the $30^{\circ}$ inclination angle at tip-B only reaches 0.022 , which is 
much smaller than the normalized crack growth of 0.55 for the $60^{\circ}$ inclination angle of the microcrack. During the cooling stage $(\mathrm{t}=14800 \mathrm{~s}, 29900 \mathrm{~s}, 44900 \mathrm{~s})$ as shown in thermal loading history (Fig. 3), the stress significantly decreases to zero in room temperature and hence it is not obvious to see the green part indicating the CMAS infiltration in Figs. 19b, 19e, 19f and 19g. Fig. 20 shows the comparison of failure behaviors between finite element method and experiment method. Note that the obtained crack propagation behavior based on our proposed numerical model yields an excellent agreement with those provided in experiment [17].

The vertical crack is easily generated in columnar microstructure induced by dynamic CMAS infiltration during thermal loading. For energy release rate analysis, the driving force at vertical cracks is obviously larger than that at horizontal cracks induced by dynamic CMAS infiltration. Based on fracture mechanics point of view, the vertical microcrack is most likely to propagate under dynamic CMAS infiltration since the open-mode stress always attains its maximum value for vertical cracks as shown in Fig. 12.

\section{Conclusions}

This study investigates the effect of CMAS infiltration on microcracks embedded in the columnar-structured TBCs by examining the temperature, stress fields, and energy release rate. A finite element model simulating the CMAS infiltration and the columnar microstructure of TC layer is used to carry out the numerical analysis. The influence of the CMAS infiltration on the temperature, heat flux, opening-mode stress, sliding-mode stress, and energy release rate of the system is examined. The energy release rate is found to increase with the CMAS infiltration depth and mismatch of thermal expansion between the CMAS and TC layer. Both the stress and energy release rate near the microcrack are found to dramatically increase when the CMAS reached the microcrack. It is observed that the material properties, including the heat conductivity and thermal expansion coefficient of CMAS, location of the microcrack, and density of microcracks, play an important role in determining the energy release rate and temperature distribution in the TC layer. Increasing the CMAS infiltration time could negate the thermal insulation provided by the TC layer and promote the energy release rate to induce microcrack propagation. Furthermore, the microcrack propagation induced by dynamic CMAS infiltration is studied by XFEM method 
in this work which demonstrates that the vertical crack easily forms and coalesces with adjacent microcracks, thereby resulting in failure via delamination.

\section{Acknowledgement}

This work was sponsored by NSFC (1171101165 and 11602246). 


\section{References}

[1] Padture NP, Gell M, Jordan EH. Thermal barrier coatings for gas-turbine engine applications. Science 2002, 296: 280-284.

[2] Miller RA. Thermal Barrier Coatings for Aircraft Engines: History and Directions. $J$ Therm Spray Technol 1997, 6: 35-42.

[3] Gleeson B. Thermal barrier coatings for aeroengine applications. J Propul Power 2006, 22: $375-383$.

[4] Mauer G, Vaßen R. Coatings with Columnar Microstructures for Thermal Barrier Applications. Adv Eng Mater, 2019.

[5] Swadźba R, Wiedermann J, Swadźba L, Hetmańczyk M, Witala B, Schulz U, Jung T. High temperature oxidation of EB-PVD TBCs on Pt-diffused single crystal Ni superalloy. Surf Coat Technol 2014, 260: 2-8.

[6] Ganvir A, Joshi S, Markocsan N, Vassen R. Tailoring columnar microstructure of axial suspension plasma sprayed TBCs for superior thermal shock performance. Mater Des 2018, 144: 192-208.

[7] Niessen KV, Gindrat M. Plasma spray-PVD: a new thermal spray process to deposit out of the vapor phase. J Therm Spray Technol 2011, 20: 736-743.

[8] Evans AG, Mumm DR, Hutchinson JW, Meier GH, Pettit FS. Mechanisms controlling the durability of thermal barrier coatings. Prog Mater Sci 2001, 46: 505-553.

[9] Sampath S, Schulz U, Jarligo MO, Kuroda S. Processing science of advanced thermalbarrier systems. Mrs Bull 2012, 37: 903-910.

[10] Krämer S, Faulhaber S, Chambers M, Clarke DR, Levi CG, Hutchinson JW. Evans A.G. Mechanisms of cracking and delamination within thick thermal barrier systems in aeroengines subject to calcium-magnesium-alumino-silicate (CMAS) penetration. Mater Sci Eng: A 2008, 490: 26-35. 
[11] Kueppers U, Cimarelli C, Hess KU, Taddeucci J, Wadsworth FB, Dingwell DB.

The thermal stability of Eyjafjallajökull ash versus turbine ingestion test sands. $J$ Appl Volcanol 2014, 3: 1-11.

[12] Clarkson RJ, Majewicz EJ. Mack P. A re-evaluation of the 2010 quantitative understanding of the effects volcanic ash has on gas turbine engines. Proc Inst Mech Eng. Part G J Aerosp Eng 2016, 0: 1-18.

[13] Borom MP, Johnson CA, Peluso LA. Role of environment deposits and operating surface temperature in spallation of air plasma sprayed thermal barrier coatings. Surf Coat Technol 1996, 86-87: 116-126.

[14] MercerC, Faulhaber S, Evans AG. Darolia R. A delamination mechanism for thermal barrier coatings subject to calcium-magnesium-alumino-silicate (CMAS) infiltration. Acta Mater 2005, 53: 1029-1039.

[15] Krämer S, Yang J, Levi CG, Johnson CA. Thermochemical interaction of thermal barrier coatings with molten $\mathrm{CaO}-\mathrm{MgO}-\mathrm{Al}_{2} \mathrm{O}_{3}-\mathrm{SiO}_{2}$ (CMAS) deposits. J Am Ceram Soc 2006, 89: $3167-3175$

[16] Li L, Clarke DR. Effect of CMAS infiltration on radiative transport through an EB-PVD thermal barrier coating. Int J Appl Ceram Technol 2008, 5: 278-288.

[17] Steinberg L, Mikulla C, Naraparaju R, Toma F-L, Großmann H, Schulz U, and Levens C. Erosion resistance of CMAS infiltrated sacrificial suspension sprayed alumina top layer on EB-PVD 7YSZ coatings Wear 2019, 438-439: 203064.

[18] Chen X. Calcium-magnesium-alumina-silicate (CMAS) delamination mechanisms in EB-PVD thermal barrier coatings. Surf Coat Technol 2006, 200: 3418-3427.

[19] $\mathrm{Su} \mathrm{L}$, Yi C. Effects of CMAS penetration on the delamination cracks in EB-PVD thermal barrier coatings with curved interface. Ceram Int 2017, 43: 8893-8897.

[20] Fan XL, Xu R, Zhang WX, Wang TJ. Effect of periodic surface cracks on the interfacial fracture of thermal barrier coating system. Appl Surf Sci 2012, 258: 9816-9823. 
[21] Fan XL, Zhang WX, Wang TJ, Liu GW, Zhang JH. Investigation on periodic cracking of elastic film/substrate system by the extended finite element method. Appl Surf Sci. 2011, 257: 6718-6724.

[22] Fan XL, Zhang WX, Wang TJ, Sun Q. The effect of thermally grown oxide on multiple surface cracking in air plasma sprayed thermal barrier coating system. Surf Coat Technol 2012, 208: 7-13.

[23] Li B, Fan XL, Okada H, Wang TJ. Mechanisms governing the failure modes of dense vertically cracked thermal barrier coatings. Eng Fract Mech 2018, 189: 451-480.

[24] Zhang WW, Li GR, Zhang Q, Yang GJ. Comprehensive damage evaluation of localized spallation of thermal barrier coatings. J Adv Ceram 2017, 6: 230-239.

[25] Mao W, Wang Y, Shi J, Huang H, Wang Y, Lv L, Yang H, Zou C, Dai C, Zhu X, Fang D. Bending fracture behavior of freestanding $\left(\mathrm{Gd}_{0.9} \mathrm{Yb}_{0.1}\right)_{2} \mathrm{Zr}_{2} \mathrm{O}_{7}$ coatings by using digital image correlation and FEM simulation with 3D geometrical reconstruction, $J$ Adv Ceram 2017, 8: 564-575.

[26] Jiang P, Fan XL, Sun YL, Li DJ, Wang TJ. Bending-driven failure mechanism and modelling of double-ceramic-layer thermal barrier coating system. Int J Solids Struct 2018, 130: $11-20$.

[27] Jiang P, Fan XL, Sun YL, Li DJ, Li B, Wang TJ. Competition mechanism of interfacial cracks in thermal barrier coating system. Mater Design 2017, 132: 559-566.

[28] Zhang GH, Fan XL, Xu R, Su LC, Wang TJ. Transient thermal stress due to the penetration of calcium-magnesium-alumino-silicate in EB-PVD thermal barrier coating system. Ceram Int 2018, 44: 12655-12663.

[29] Sun Y, Liu MB. Analysis of the crack penetration/deflection at the interfaces in the intelligent coating system utilizing virtual crack closure technique. Engineering Fracture Mechanics 2015, 133: 152-162.

[30] Van den Bosch MJ, Schreurs PJG. Geers M.G.D. A cohesive zone model with alarge displacement formulation accounting for interfacial fibrillation. Eur J Mech/A Sol 2007, 26: $1-19$. 
[31] Guo F, HuangK, Guo L, Bai X, Zhong S, Yu H. An interaction energy integral method for T-stress evaluation in nonhomogeneous materials under thermal loading. Mech Mater 2015, 83: 30-39.

[32] Cai ZW, Jiang JS, Wang WZ, et al. CMAS penetration-induced cracking behavior in the ceramic top coat of APS TBCs Ceram Int 2019, 45: 14366-14375.

[33] Smith M, ABAQUS User's Manual. D.S.M.S. Corporation, 2009.

[34] Naraparaju R, Chavez JJG, Schulz U, Ramana CV. Interaction and infiltration behavior of Eyjafjallajökull, Sakurajima volcanic ashes and a synthetic CMAS containing FeO with/in EB-PVD $\mathrm{ZrO}_{2}-65 \mathrm{wt} \% \mathrm{Y}_{2} \mathrm{O}_{3}$ coating at high temperature. Acta Mater 2017, 136: 164-180.

[35] Belytschko T, Gracie R, Ventura G. A review of extended/generalized finite element methods for material modeling. Model Simul Mater Sci Eng 2009, 17: 043001.

[36] Alfano G, Crisfield MA. Finite element interface models for the delamination analysis of laminated composites: Mechanical and computational issues. Int Numer Methods Eng 2001, 50: $1701-1736$.

[37] Zhu W, Yang L, Guo JW, Zhou YC, Lu C. Determination of interfacial adhesion energies of thermal barrier coatings by compression test combined with a cohesive zone finite element model. Int J Plast 2015, 64: 76-87.

[38] Wan J, Zhou M, Yang XS, et al. Fracture characteristics of freestanding 8wt\% Y2O3$\mathrm{ZrO} 2$ coatings by single edge notched beam and Vickers indentation tests. Mater Sci Eng 2013, 581: 140-144.

[39] Rabiei A, Evans AG. Falure mechanism associated with the thermally grown oxide in plasma-sprayed thermal barrier coatings. Acta Mater 2000, 48: 3963-3976.

[40] Jackson RW, Zaleski EM, Poerschke DL, Hazel BT, Begley MR. Interaction of molten silicates with thermal barrier coatings under temperature gradients. Acta Mater 2015, 89: 396-407. 
[41] Ranibar-Far M, Absi J, Mariaux G, Dubois F. Simulation of the effect of material properties and interface roughness on the stress distribution in thermal barrier coatings using finite element method. Mater Design 2010, 31: 772-781.

[42] Kakuda TR, Levi CG, Bennett TD. The thermal behavior of CMAS-infiltrated thermal barrier coatings. Surf Coat Technol 2015, 272: 350-356.

[43] Valerie NPB, Wiesner L. Mechanical and thermal properties of calcium-magnesium aluminosilicate (CMAS) glass. J Eur Ceram Soc 2015, 35: 2907-2914.

[44] Liu A, Wei Y. Finite element analysis of anti-spallation thermal barrier coatings. Surf Coat Technol 2003, 165: 154-162. 
Table 1. Material properties of the TBCs, CMAS, and highly porous oxides [26, 28, 40-44]

\begin{tabular}{lllllll}
\hline Material name & $E(\mathrm{GPa})$ & $v$ & $\rho\left(\mathrm{kg} / \mathrm{m}^{3}\right)$ & $K(\mathrm{~W} / \mathrm{mK})$ & $\alpha \times 10^{-1}\left({ }^{\circ} \mathrm{C}^{-1}\right)$ & $c \times 10^{-6}(\mathrm{~J} / \mathrm{kgK})$ \\
\hline Top coat & 40 & 0.2 & 5650 & 1.05 & 11 & 483 \\
Bond coat & 180 & 0.3 & 7320 & 6.4 & 16 & 592 \\
Substrate & 280 & 0.3 & 8220 & 17.3 & 14 & 524 \\
High porosity oxides & 2 & 0.25 & 1000 & 0.2 & 11 & 483 \\
CMAS & 84 & 0.25 & 2540 & $\mathrm{P}$ & $\mathrm{P}$ & 875 \\
\hline
\end{tabular}
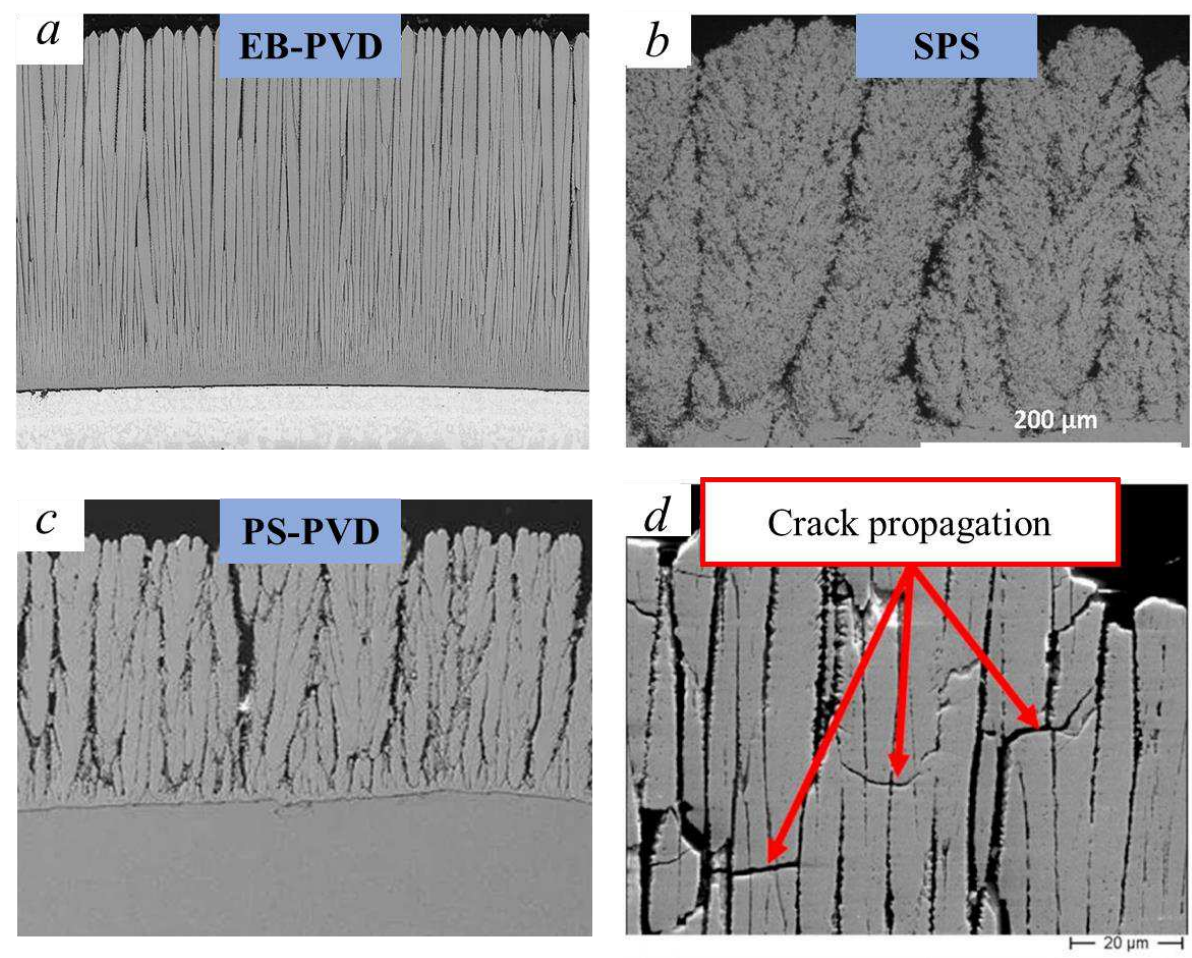

Fig. 1. SEM images of a columnar-structure deposited by (a) EB-PVD [5] (b) SPS [6] (c) PSPVD [7] TBCs and (d) infiltrated EB-PVD areas: cracks propagated induced by CMAS through several columns [17] 


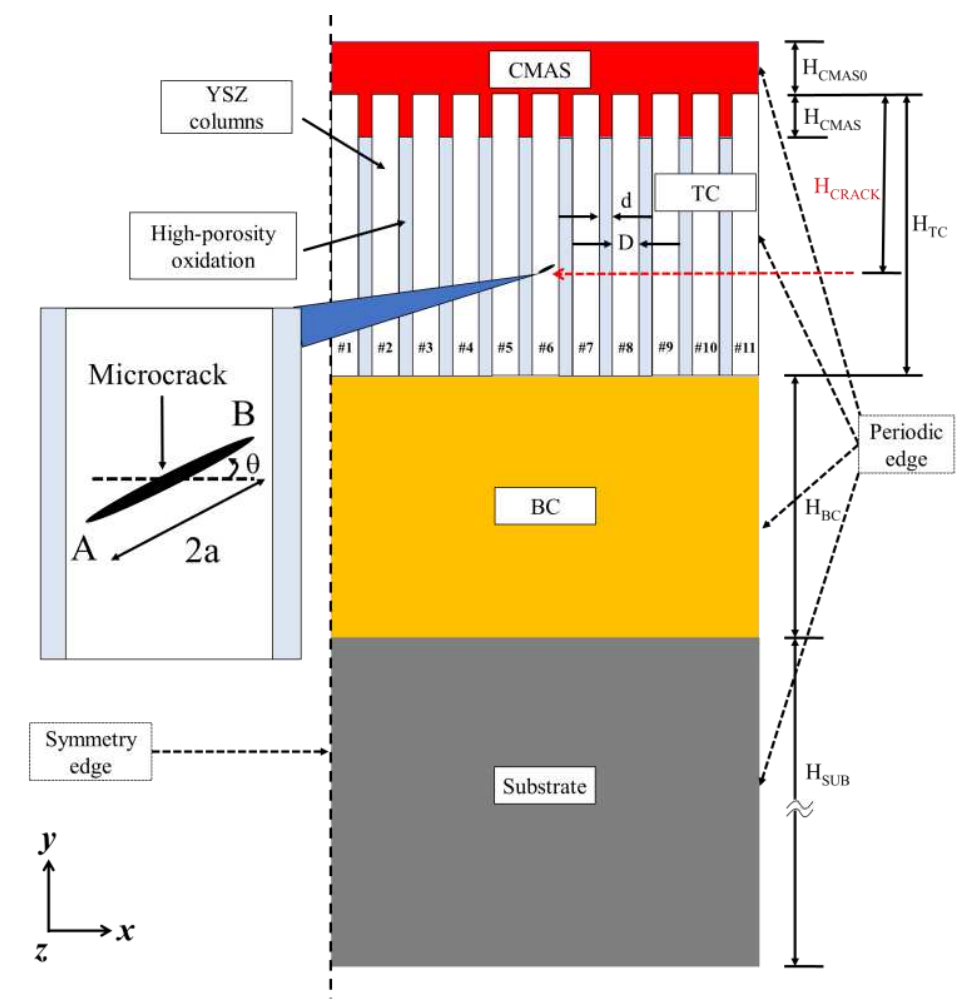

Fig. 2. A schematic view of the finite element model incorporating the columnar microstructure of the columnar-structured TBCs

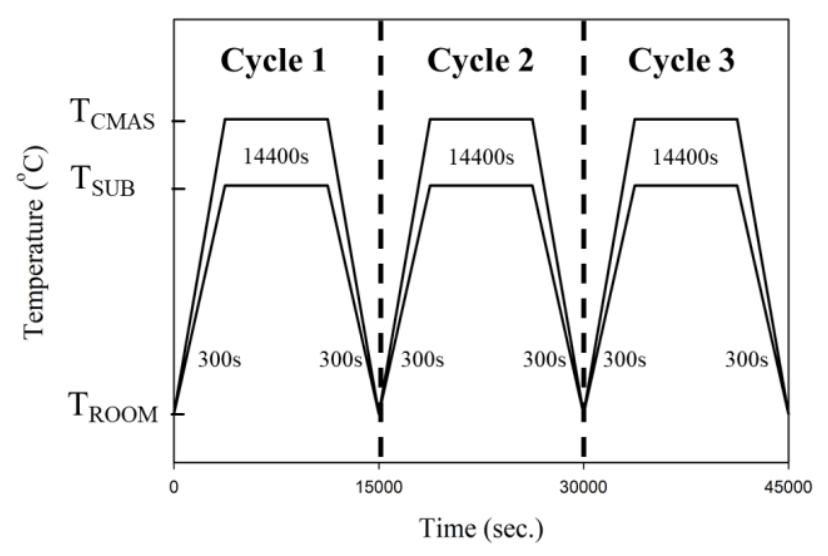

Fig. 3. Thermal loading history 


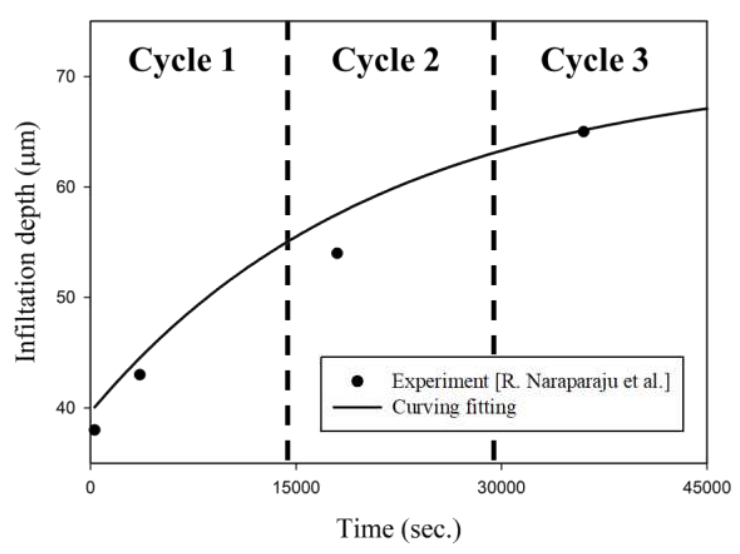

Fig. 4. Comparisons of the infiltration depths obtained by experiment [34] (scattered points) with the curve fitted with Eq. (1) (solid line)

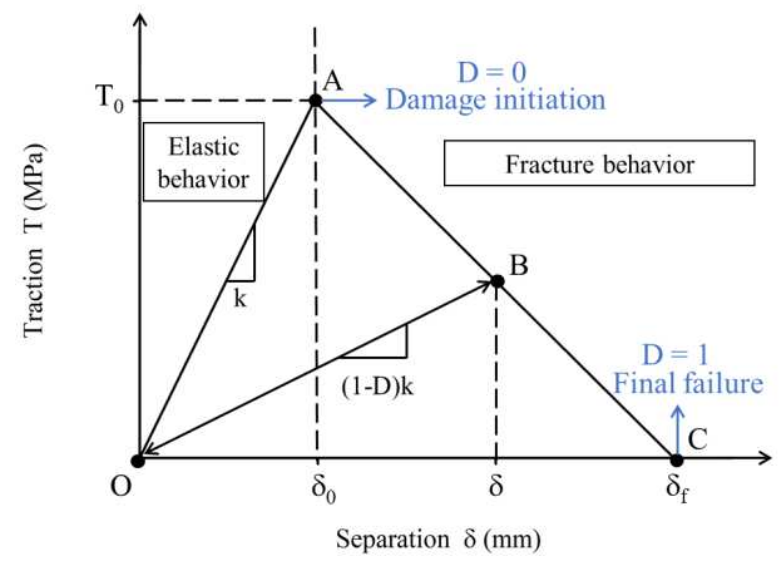

Fig. 5. Linear traction-separation law

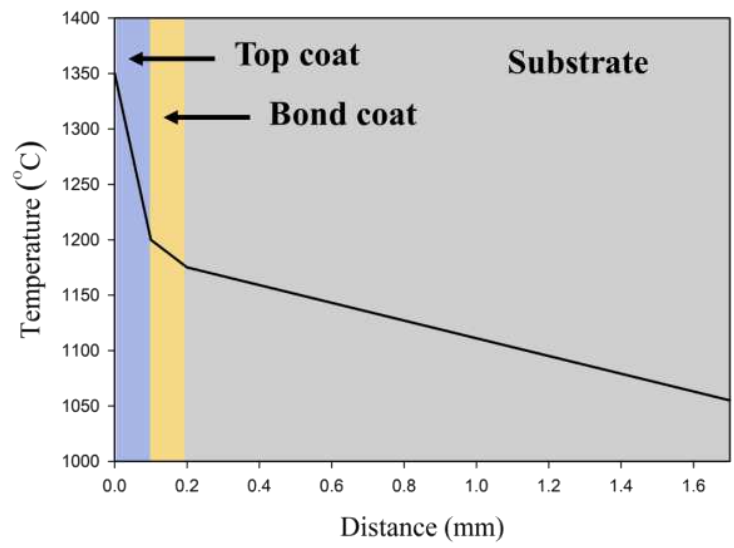

Fig. 6. Temperature distribution in the TBC during the holding process (400 s) 


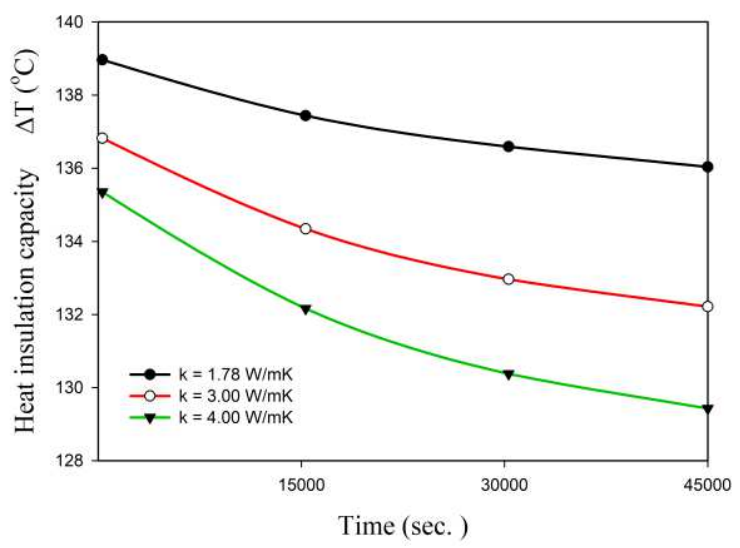

Fig. 7. Heat insulation capacity in the TC layer with three different CMAS heat conductivities $\left(\mathrm{H}_{\mathrm{CRACK}}=65 \mu \mathrm{m}\right)$

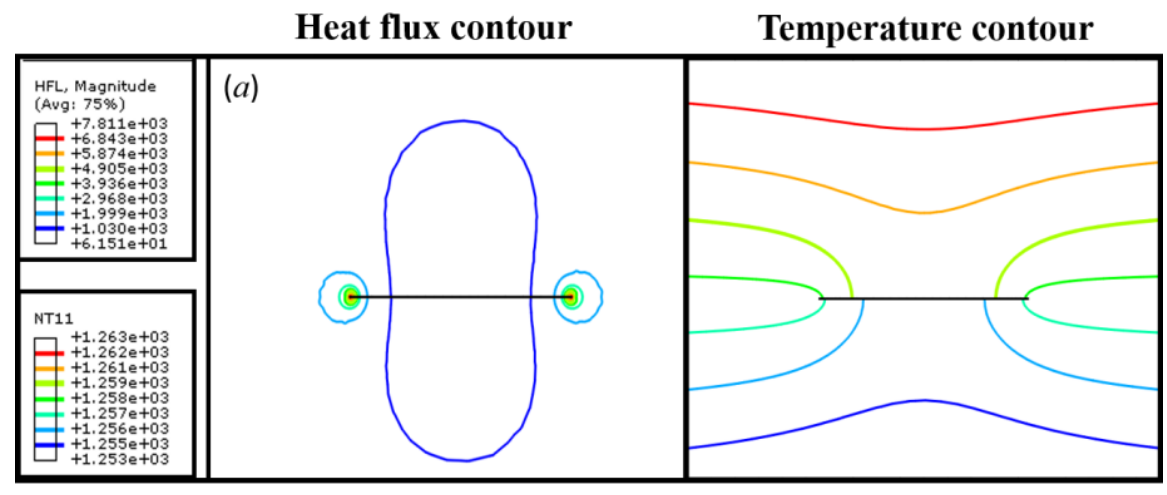

Heat flux contour

Temperature contour
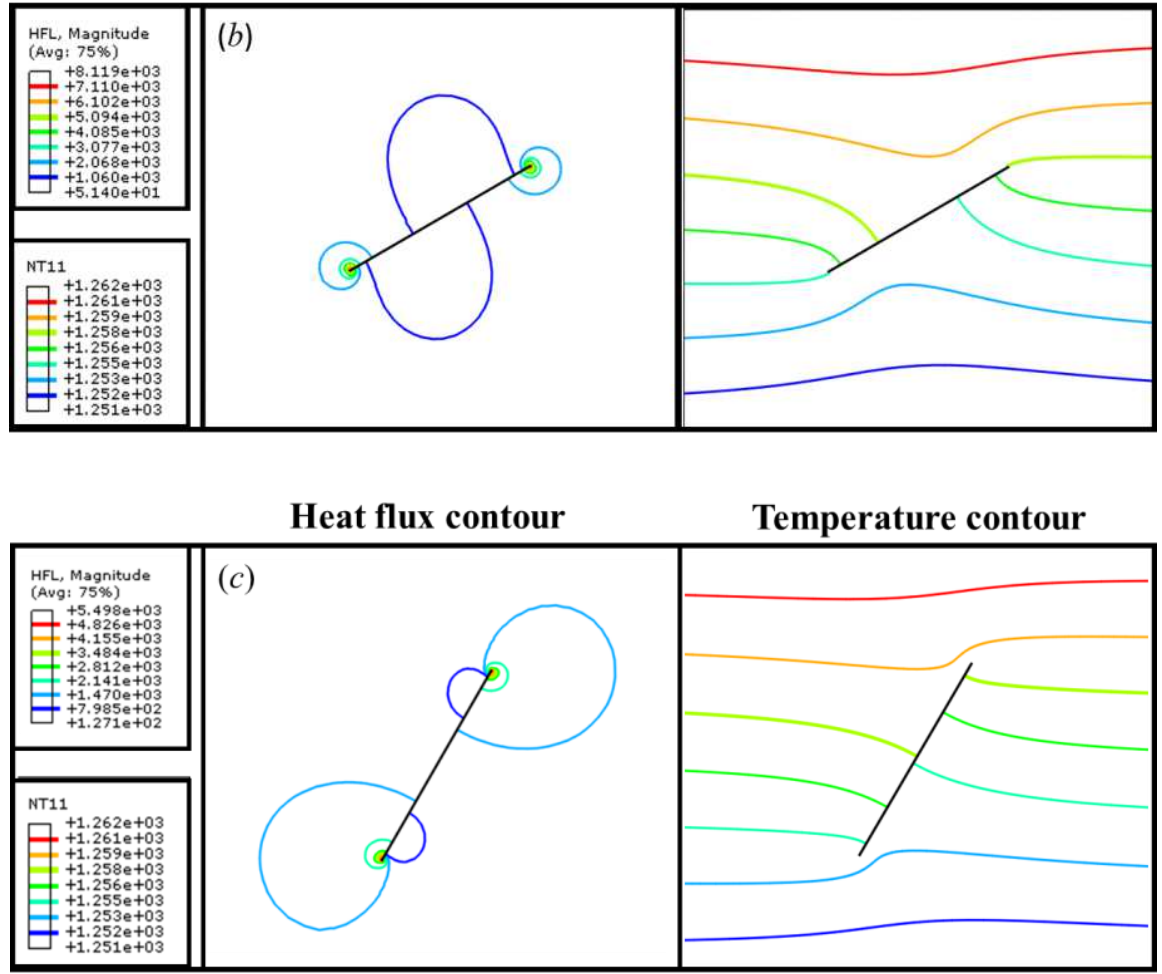


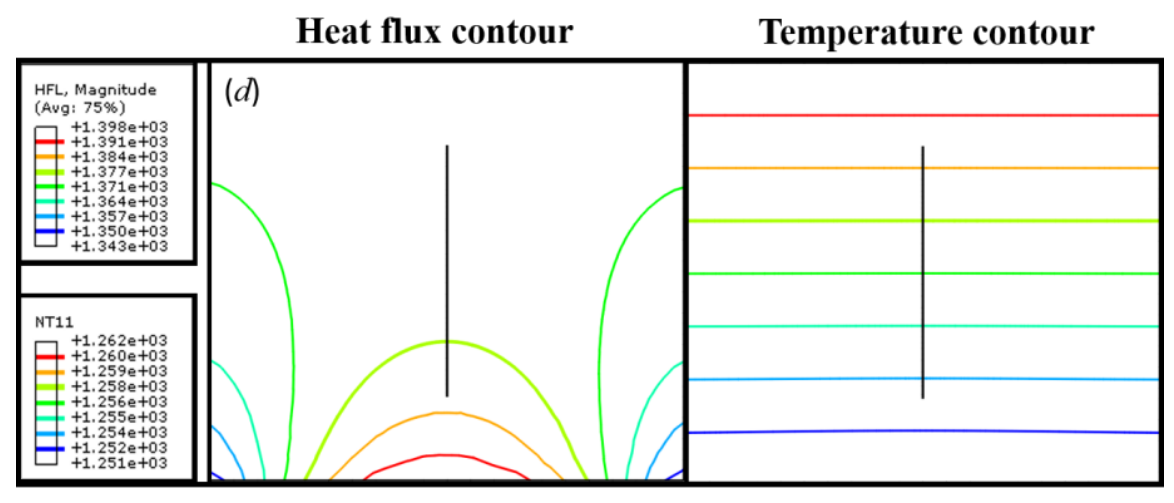

Fig. 8. Heat flux and temperature contours in the TC layer for different crack inclination angles: (a) $0^{\circ}$, (b) $30^{\circ}$, (c) $60^{\circ}$, and (d) $90^{\circ}$ (400s)

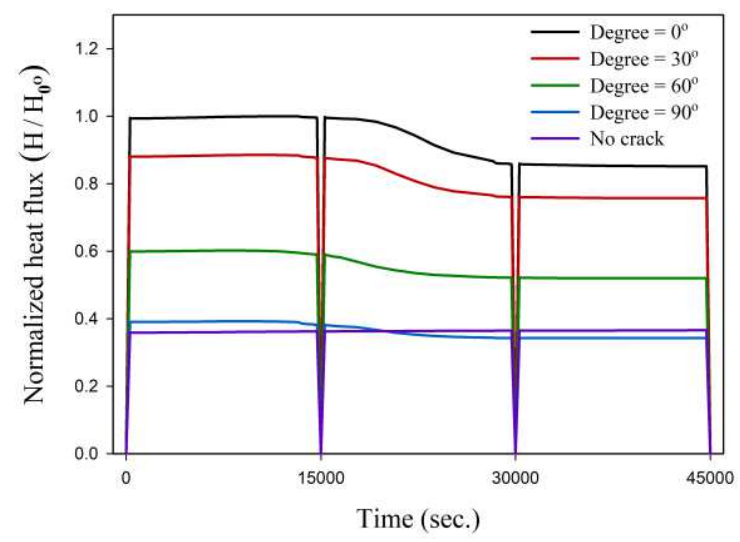

Fig. 9. Normalized heat flux at tip-B for different crack inclination angles during dynamic CMAS infiltration

$$
\left(\mathrm{H}_{\mathrm{CRACK}}=65 \mu \mathrm{m} \text { and } K_{\mathrm{CMAS}}=1.78 \mathrm{~W} / \mathrm{mK}\right)
$$

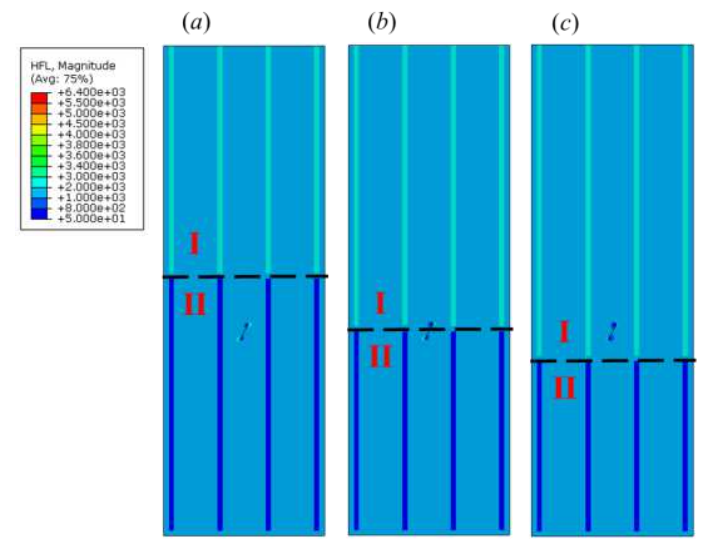

Fig. 10. Distribution of Heat flux during holding stage around the YSZ microstructure with the CMAS penetrated zone (I) and CMAS non-penetrated zone (II). (a) $t=9000$ s (b) $\mathrm{t}=24000 \mathrm{~s}(\mathrm{c}) \mathrm{t}=39000 \mathrm{~s}$

$$
\left(\mathrm{H}_{\mathrm{CRACK}}=65 \mu \mathrm{m} \text { and } K_{\mathrm{CMAS}}=1.78 \mathrm{~W} / \mathrm{mK}\right)
$$




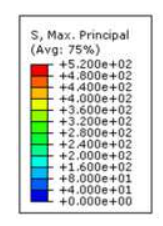

(a)

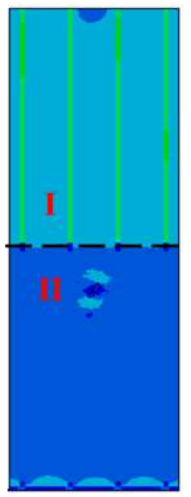

(b)

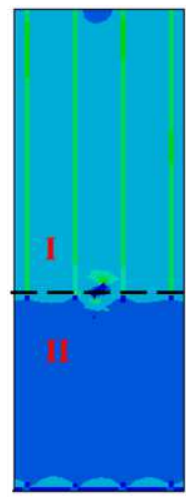

(c)

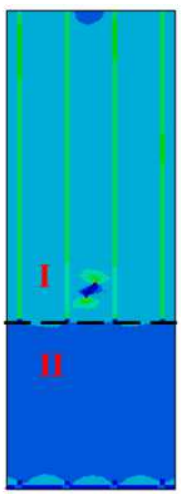

Fig. 11. Distribution of maximum principal stress during holding stage around the YSZ microstructure with the CMAS penetrated zone (I) and CMAS non-penetrated zone (II). (a) $\mathrm{t}=9000 \mathrm{~s}$ (b) $\mathrm{t}=24000 \mathrm{~s}$ (c) $\mathrm{t}=39000 \mathrm{~s}$

(a)

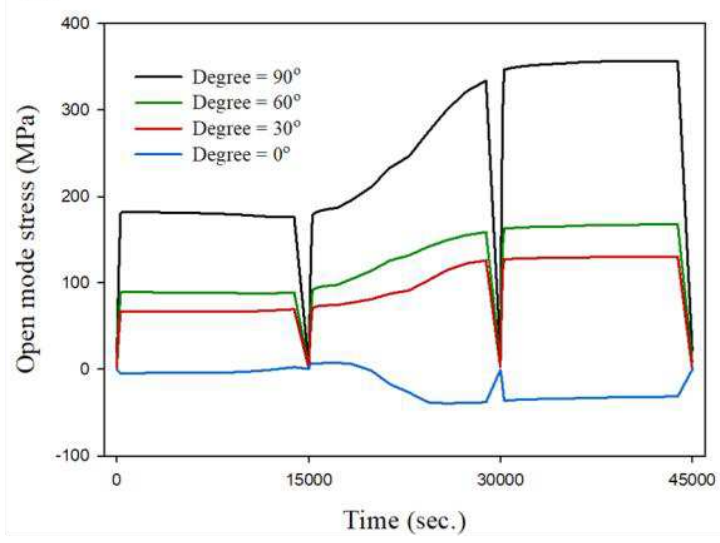

(b)

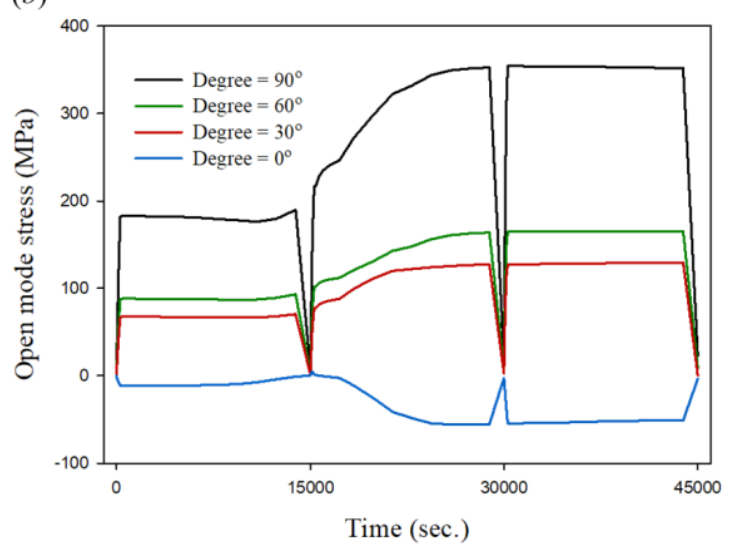

Fig. 12. Open-mode stress near the crack tip for different crack inclination angles during dynamic CMAS infiltration: (a) tip-A and (b) tip-B $\left(\mathrm{H}_{\mathrm{CRACK}}=60 \mu \mathrm{m}, \alpha_{\mathrm{CMAS}}=8.5 \times 10^{-6}\left({ }^{\circ} \mathrm{C}^{-1}\right)\right.$, and $\left.K_{\mathrm{CMAS}}=1.78 \mathrm{~W} / \mathrm{mK}\right)$

(a)

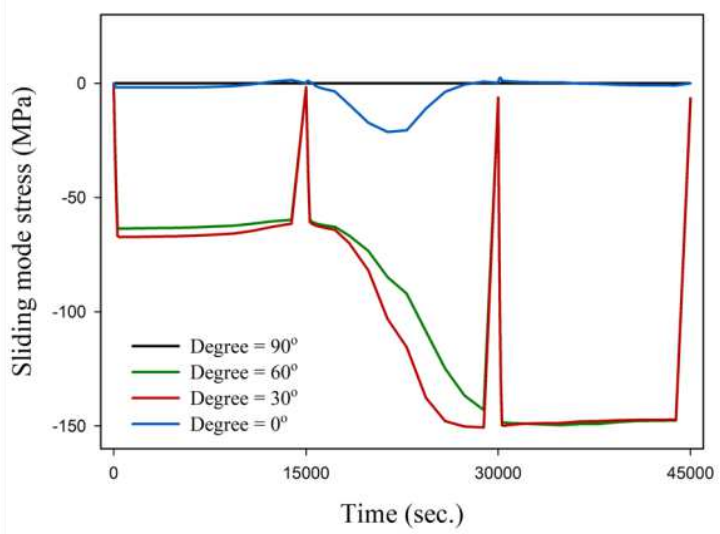

(b)

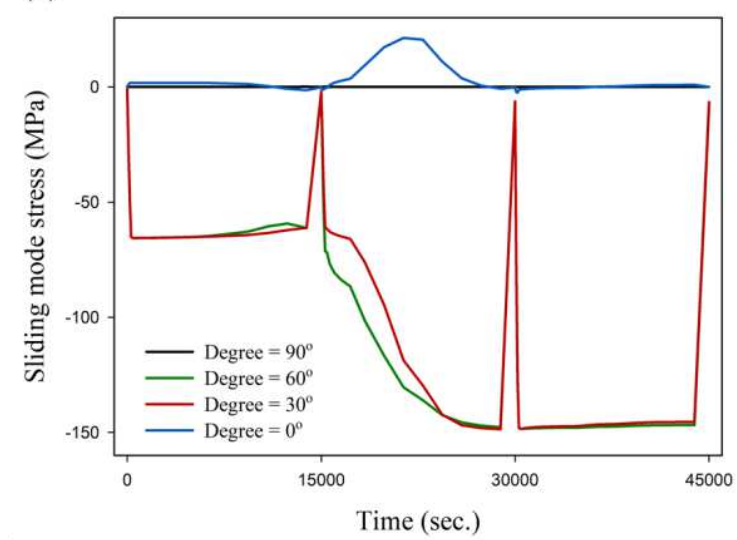

Fig. 13. Sliding-mode stress near the crack tip for different crack inclination angles during dynamic CMAS infiltration: (a) tip-A and (b) tip-B 
$\left(\mathrm{H}_{\mathrm{CRACK}}=60 \mu \mathrm{m}, \alpha_{\mathrm{CMAS}}=8.5 \times 10^{-6}\left({ }^{\circ} \mathrm{C}^{-1}\right)\right.$, and $\left.K_{\mathrm{CMAS}}=1.78 \mathrm{~W} / \mathrm{mK}\right)$

(a)

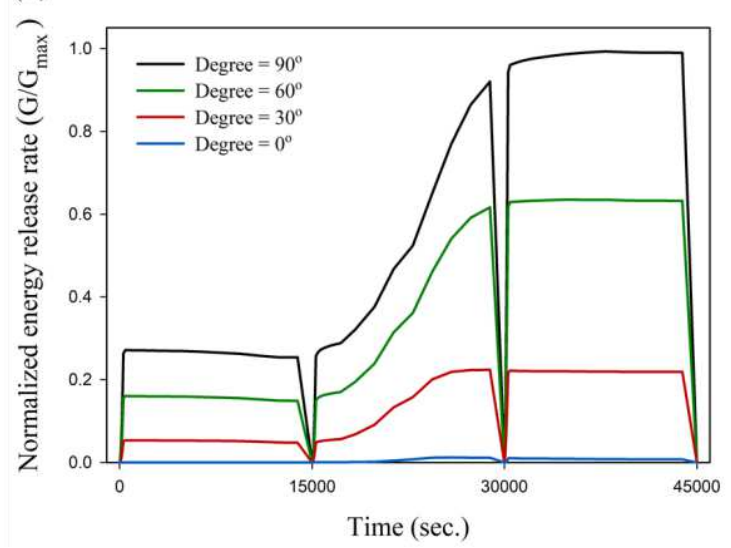

(b)

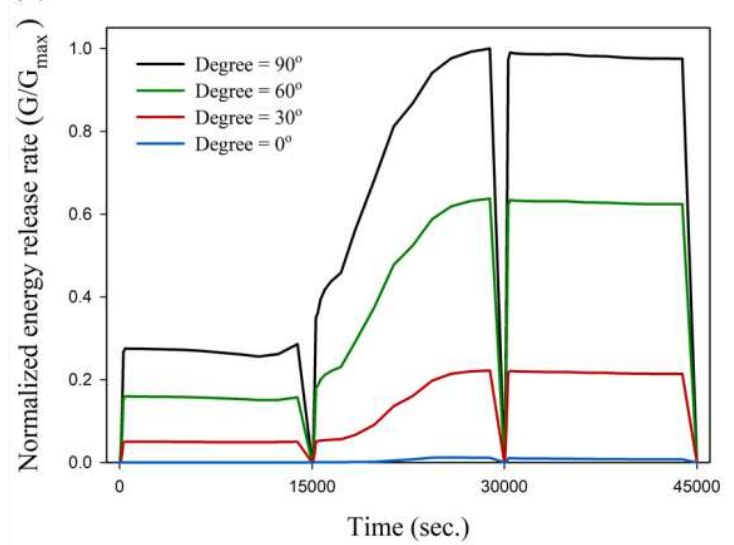

Fig. 14. Normalized strain energy release rates for different crack inclination angles during dynamic CMAS infiltration: (a) tip-A and (b) tip-B $\left(\mathrm{H}_{\mathrm{CRACK}}=60 \mu \mathrm{m}, \alpha_{\mathrm{CMAS}}=8.5 \times 10^{-6}\left({ }^{\circ} \mathrm{C}^{-1}\right)\right.$, and $\left.K_{\mathrm{CMAS}}=1.78 \mathrm{~W} / \mathrm{mK}\right)$

(a)

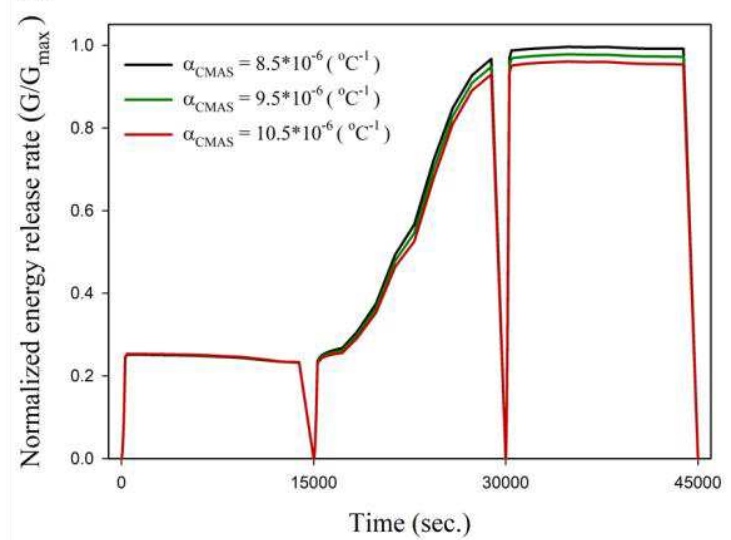

(b)

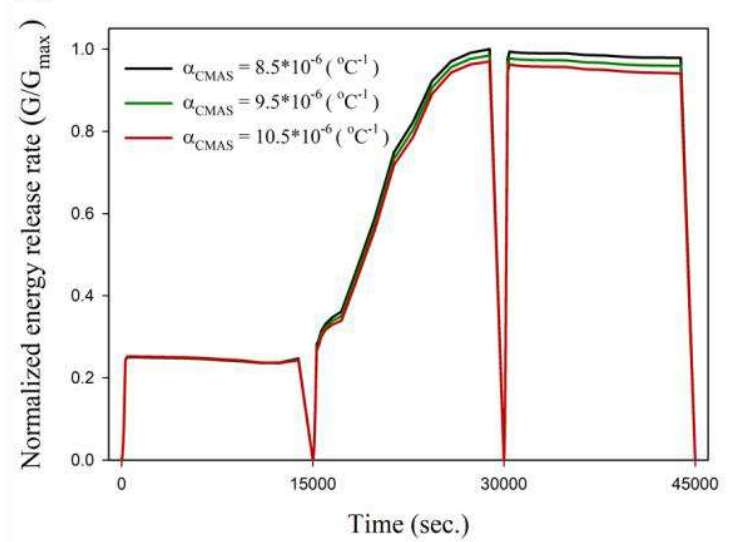

Fig. 15. Normalized strain energy release rates for different CMAS thermal expansion coefficients during dynamic CMAS infiltration: (a) tip-A and (b) tip-B

$\left(\mathrm{H}_{\mathrm{CRACK}}=60 \mu \mathrm{m}\right.$ and $\left.K_{\mathrm{CMAS}}=1.78 \mathrm{~W} / \mathrm{mK}\right)$

(a)

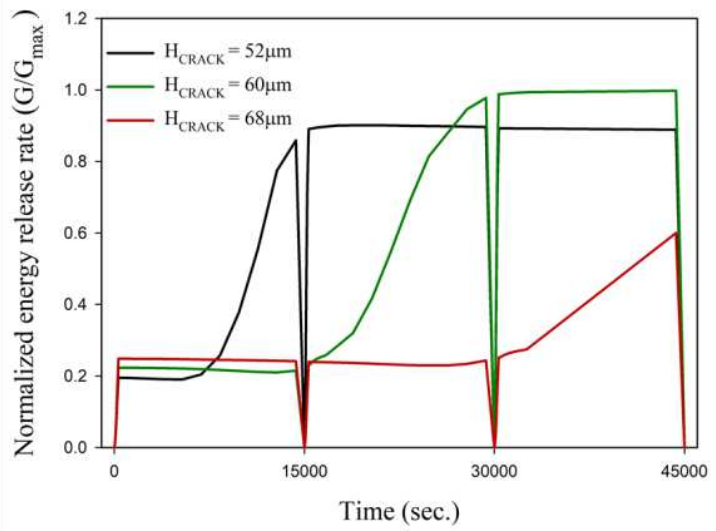

(b)

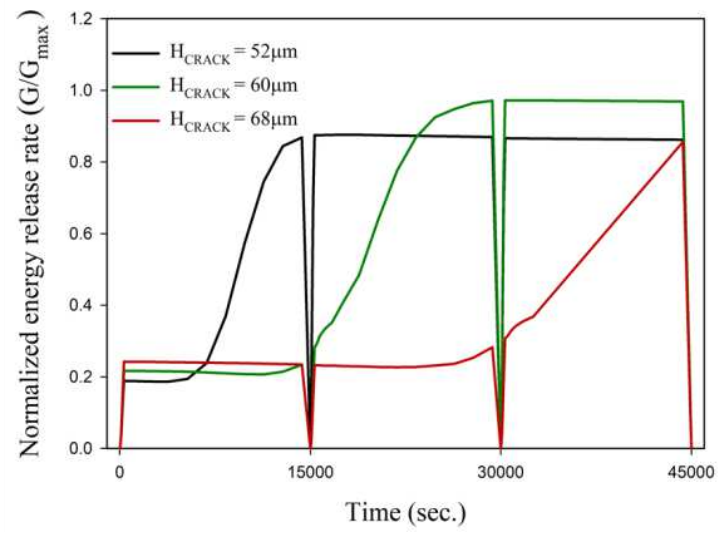


Fig. 16. Normalized strain energy release rates for different microcrack heights during CMAS dynamic infiltration: (a) tip-A and (b) tip-B

$$
\left(\alpha_{\mathrm{CMAS}}=8.5 \times 10^{-6}\left({ }^{\circ} \mathrm{C}^{-1}\right) \text { and } K_{\mathrm{CMAS}}=1.78 \mathrm{~W} / \mathrm{mK}\right)
$$

(a)

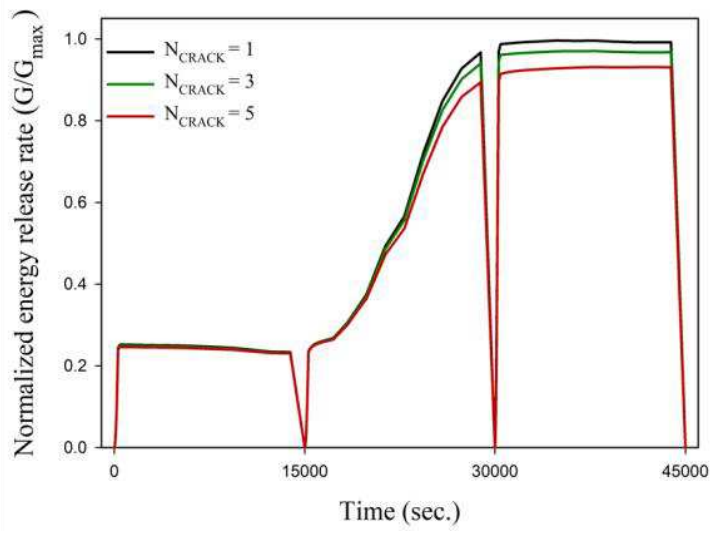

(b)

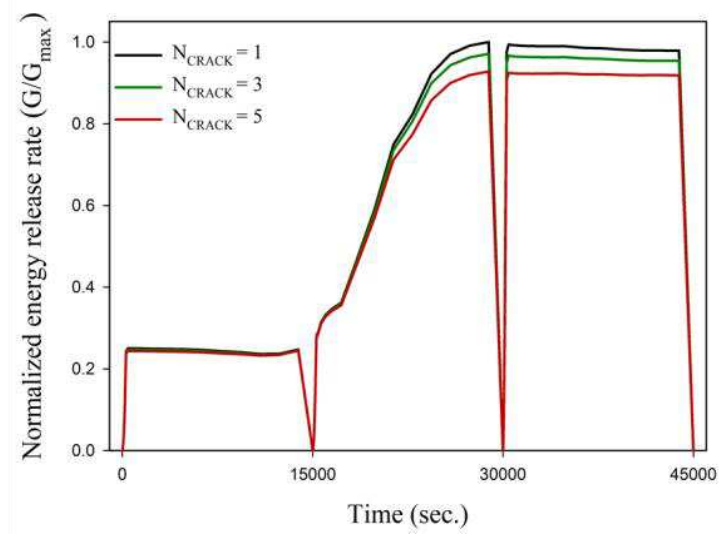

Fig. 17. Normalized strain energy release rates for different amounts of microcracks during dynamic CMAS infiltration: (a) tip-A and (b) tip-B

$\left(\mathrm{H}_{\mathrm{CRACK}}=60 \mu \mathrm{m}, \alpha_{\mathrm{CMAS}}=8.5 \times 10^{-6}\left({ }^{\circ} \mathrm{C}^{-1}\right)\right.$, and $\left.K_{\mathrm{CMAS}}=1.78 \mathrm{~W} / \mathrm{mK}\right)$

(a)

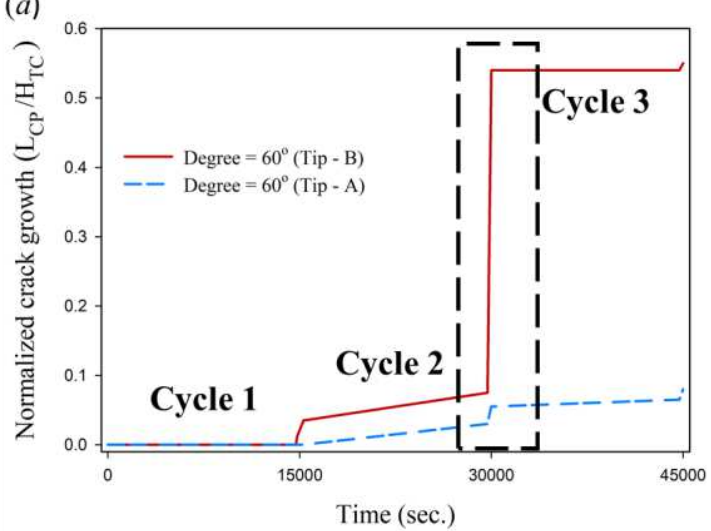

(b)

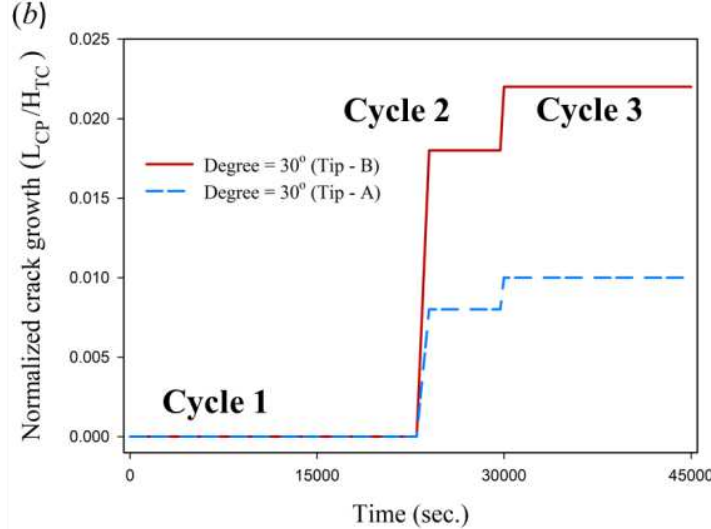

Fig. 18. Normalized crack growth for tip-A and tip-B during CMAS infiltration around \#6 YSZ column: (a) inclination angle $=60^{\circ}$ and (b) inclination angle $=30^{\circ}$ $\left(\mathrm{H}_{\mathrm{CRACK}}=60 \mu \mathrm{m}, \alpha_{\mathrm{CMAS}}=8.5 \times 10^{-6}\left({ }^{\circ} \mathrm{C}^{-1}\right)\right.$, and $\left.K_{\mathrm{CMAS}}=1.78 \mathrm{~W} / \mathrm{mK}\right)$ 
(a)

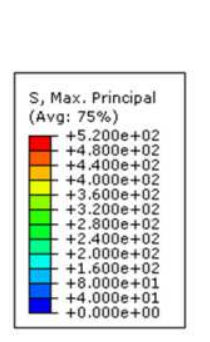

(d)

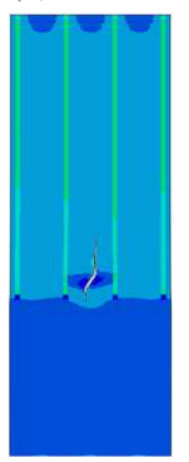

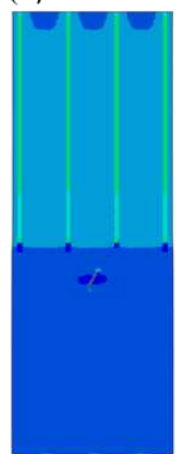

(e) (b)

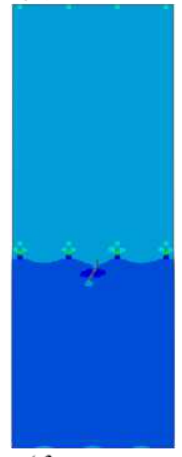

$(f)$

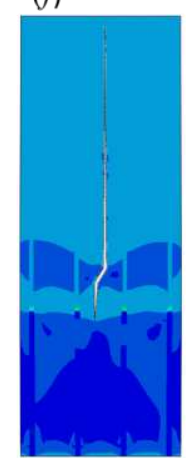

(c)

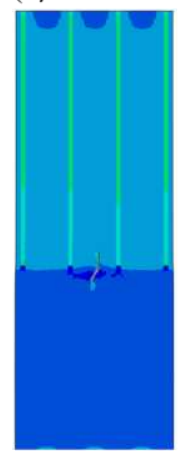

$(g)$
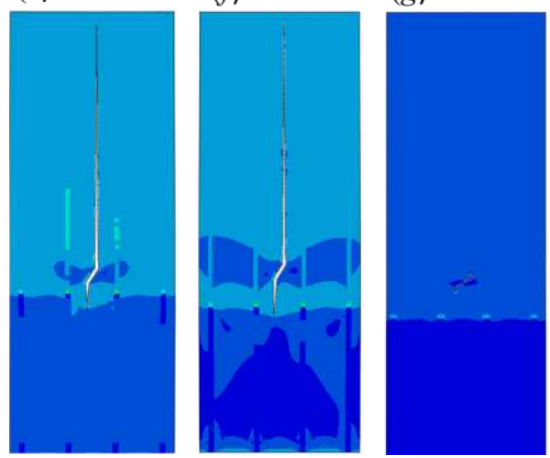

Fig. 19. Distribution of maximum principal stress around the YSZ microstructure of microcrack propagation induced by dynamic CAMS infiltration

$\left(\mathrm{H}_{\mathrm{CRACK}}=60 \mu \mathrm{m}, \alpha_{\mathrm{CMAS}}=8.5 \times 10^{-6}\left({ }^{\circ} \mathrm{C}^{-1}\right)\right.$, and $\left.K_{\mathrm{CMAS}}=1.78 \mathrm{~W} / \mathrm{mK}\right)$
(a) $\mathrm{t}=10000 \mathrm{~s}, \theta=60^{\circ}$
(b) $\mathrm{t}=14800 \mathrm{~s}, \theta=60^{\circ}$
(c) $\mathrm{t}=18000 \mathrm{~s}, \theta=60^{\circ}$
(d) $\mathrm{t}=29650 \mathrm{~s}, \theta=60^{\circ}$
(e) $\mathrm{t}=29900 \mathrm{~s}, \theta=60^{\circ}$ (f) $\mathrm{t}=44900 \mathrm{~s}, \theta=60^{\circ}$
(g) $\mathrm{t}=44900 \mathrm{~s}, \theta=30^{\circ}$

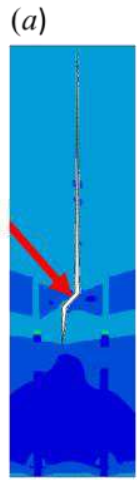

(b)

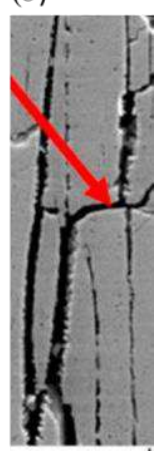

Fig. 20. Comparison of failure behavior between (a) finite element method and (b) experimental method [17] 
Figures
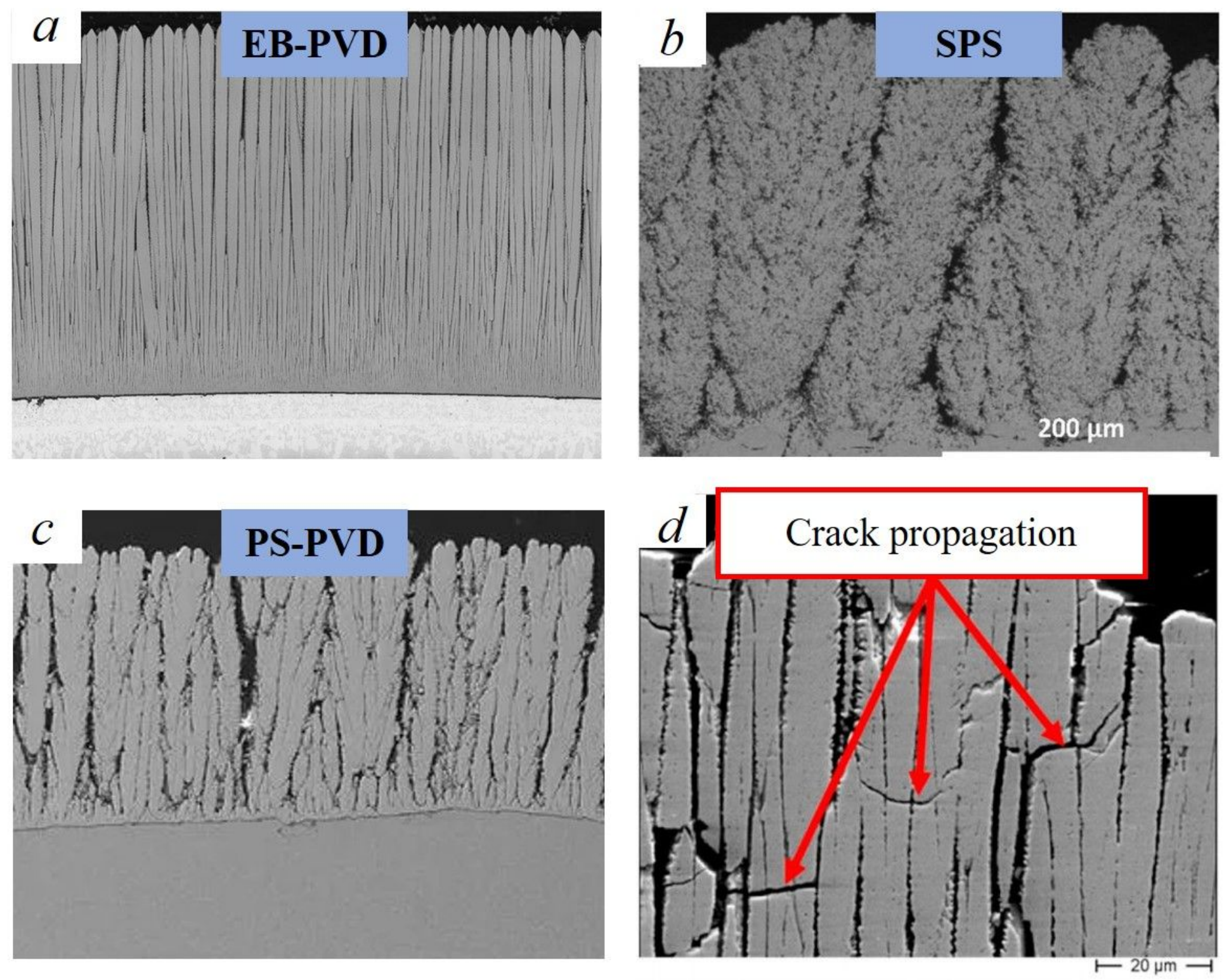

Figure 1

SEM images of a columnar-structure deposited by (a) EB-PVD [5] (b) SPS [6] (c) PS-PVD [7] TBCs and (d) infiltrated EB-PVD areas: cracks propagated induced by CMAS through several columns [17] 


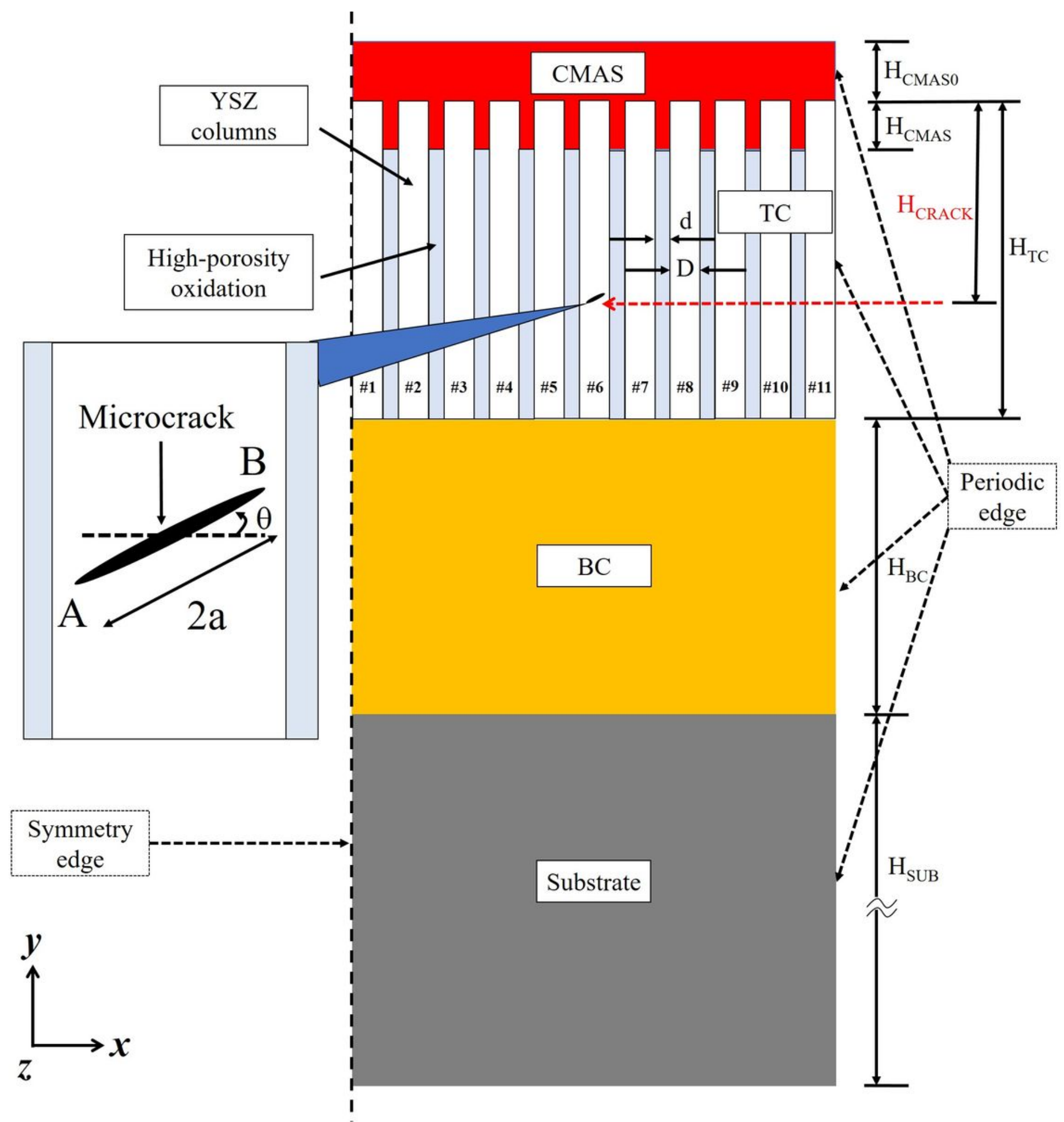

Figure 2

A schematic view of the finite element model incorporating the columnar microstructure of the columnarstructured TBCs 


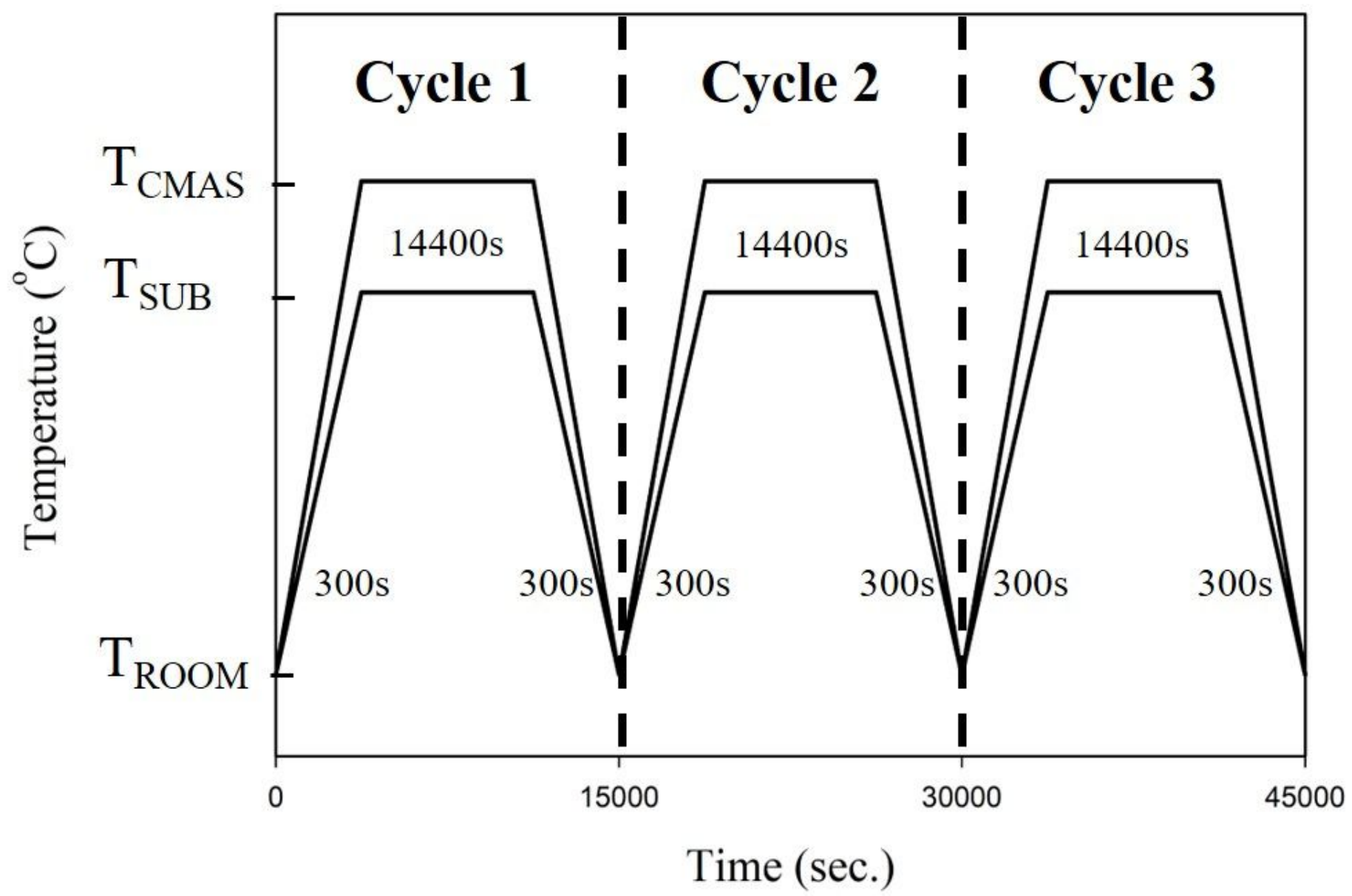

Figure 3

Thermal loading history 


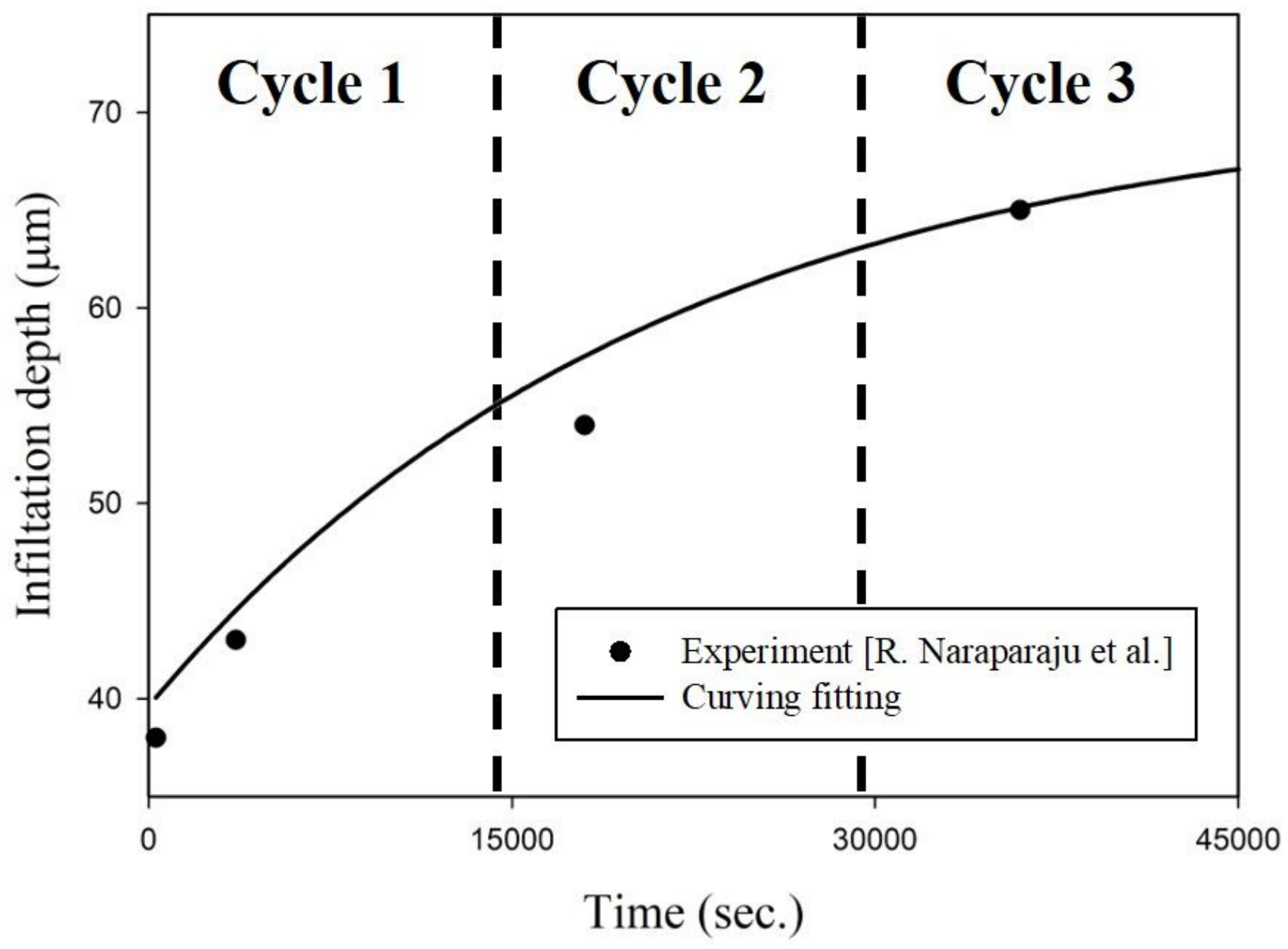

Figure 4

Comparisons of the infiltration depths obtained by experiment [34] (scattered points) with the curve fitted with Eq. (1) (solid line) 


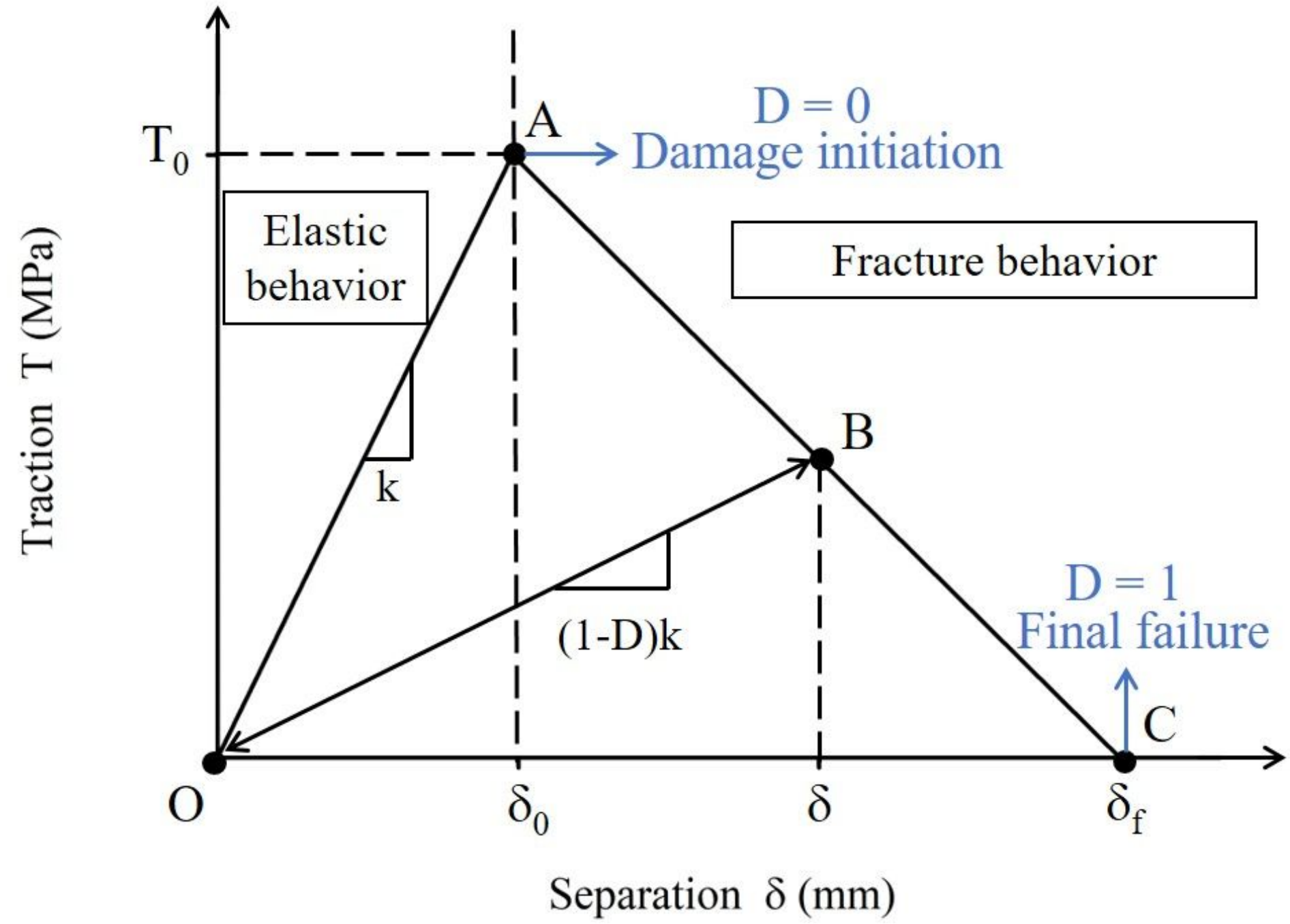

Figure 5

Linear traction-separation law 


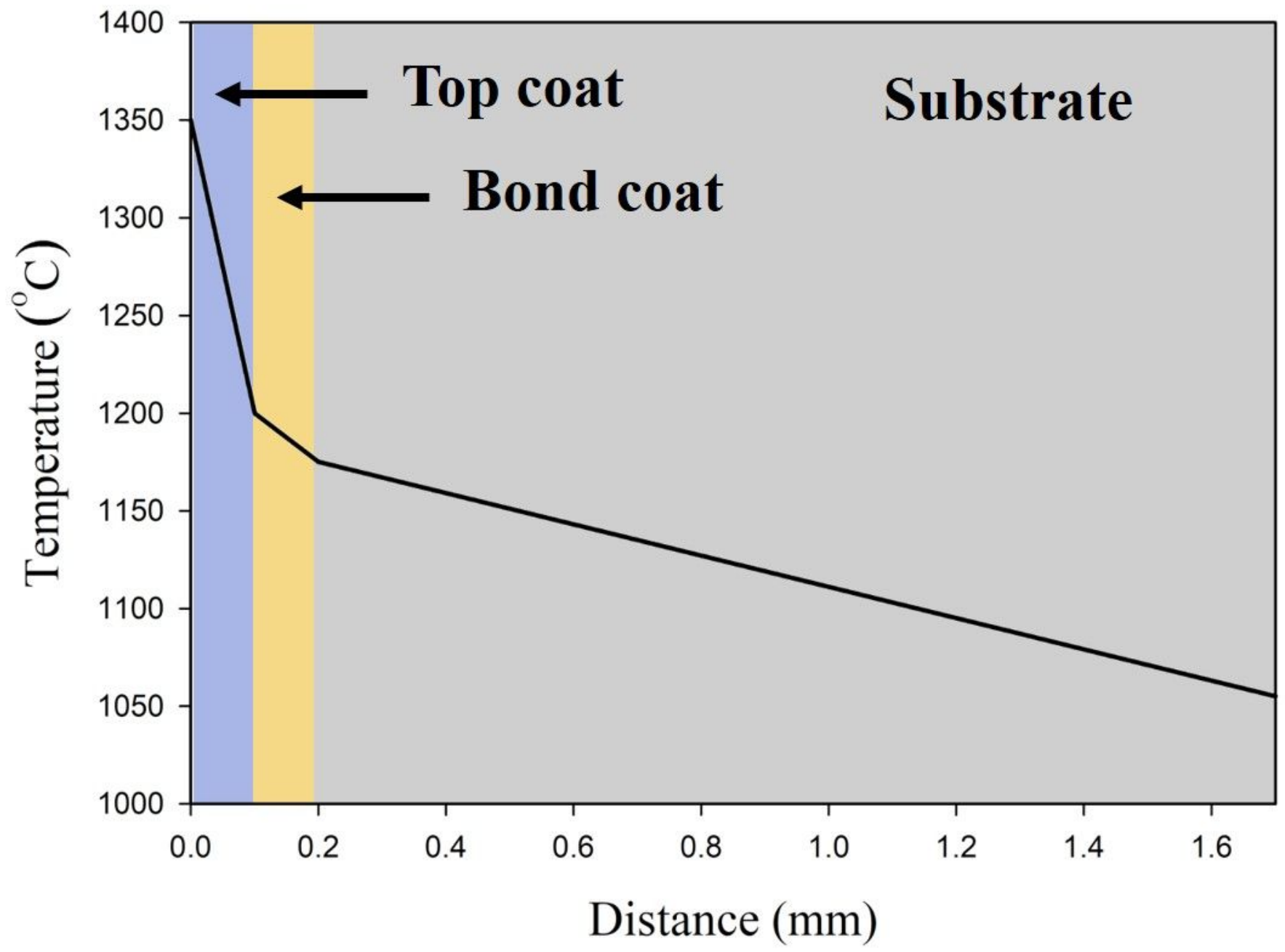

Figure 6

Temperature distribution in the TBC during the holding process (400 s) 


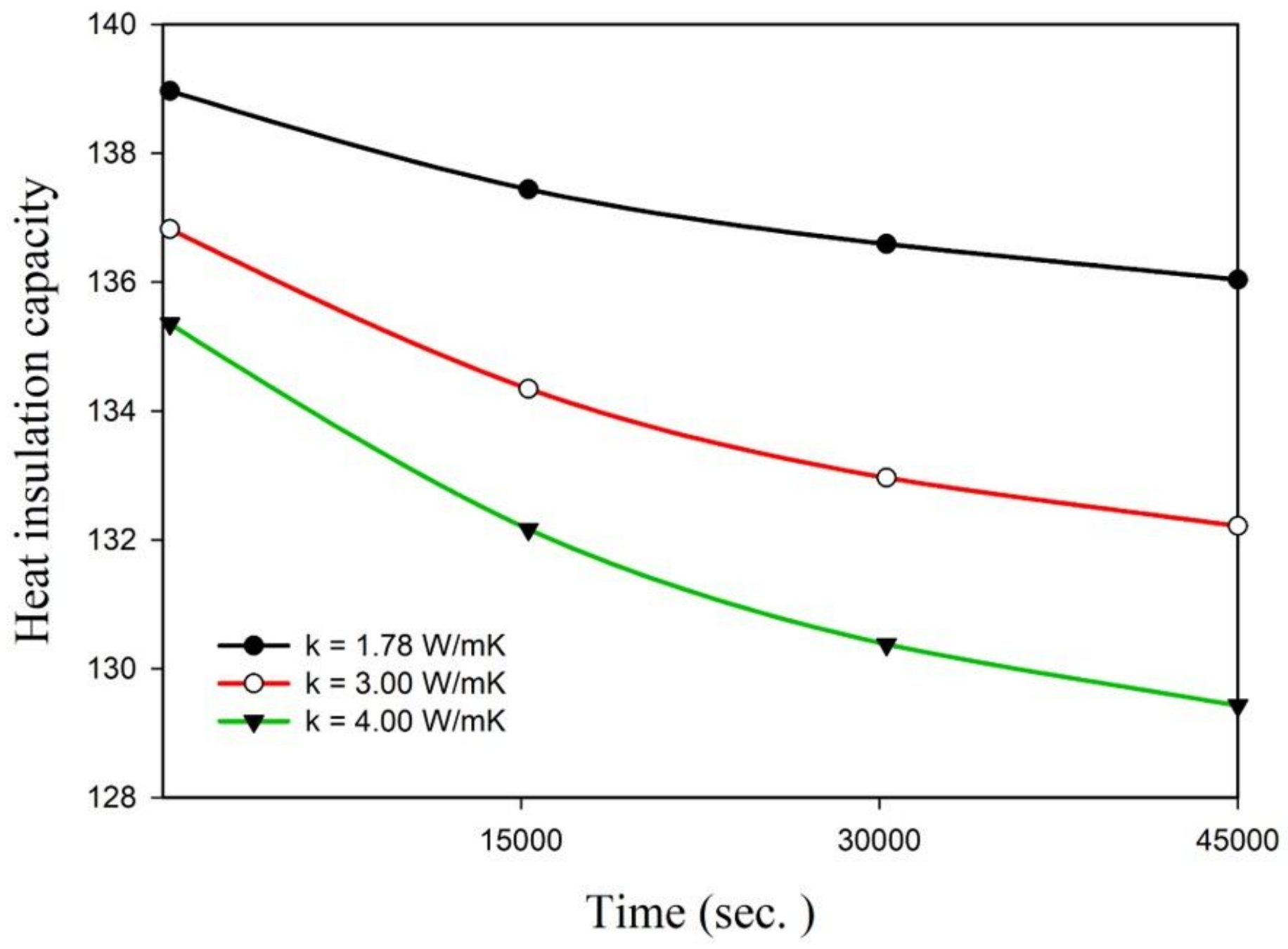

Figure 7

Heat insulation capacity in the TC layer with three different CMAS heat conductivities (HCRACK $=65 \mu \mathrm{m})$ 


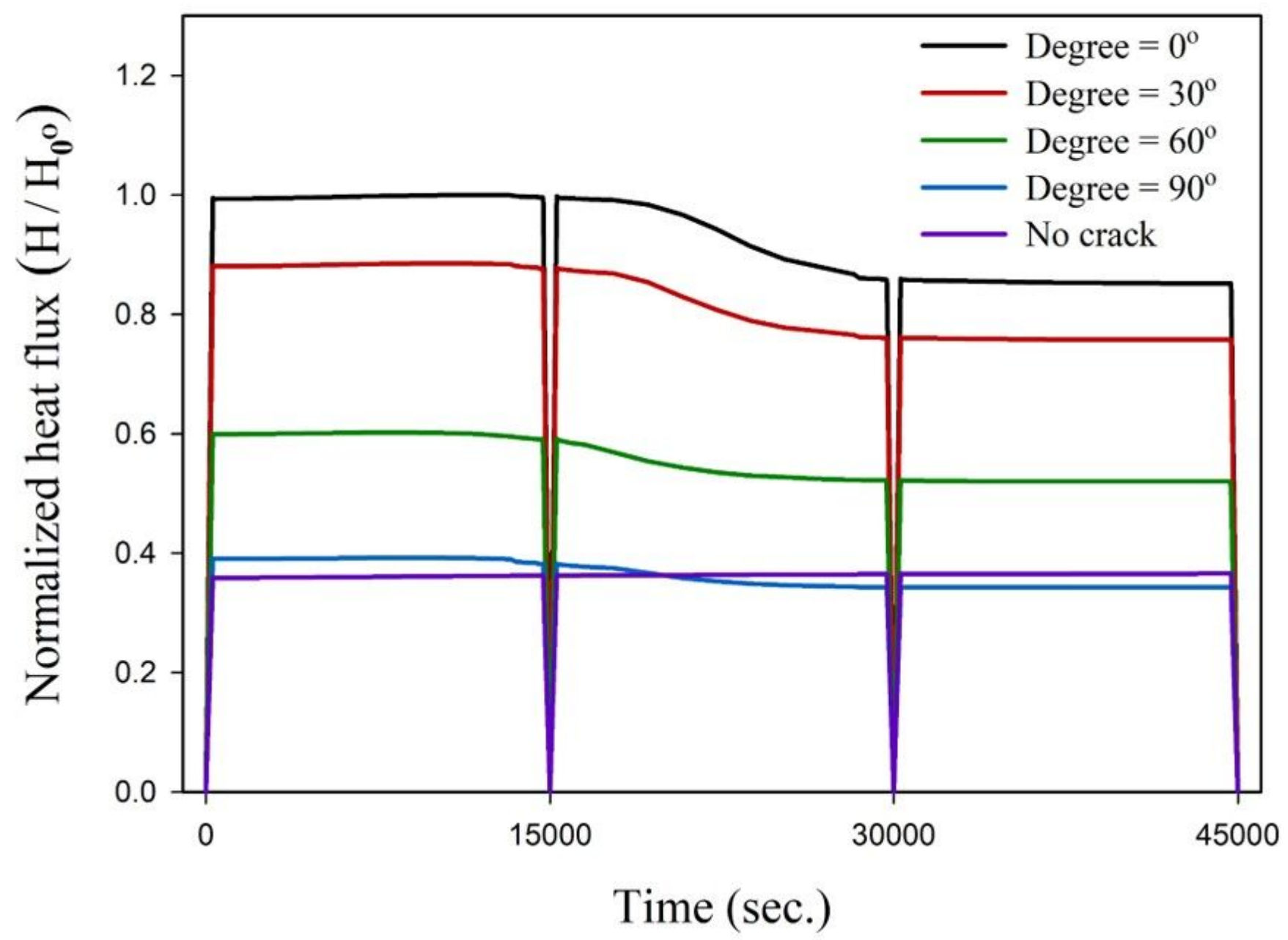

Figure 8

Normalized heat flux at tip-B for different crack inclination angles during dynamic CMAS infiltration (HCRACK $=65 \mu \mathrm{m}$ and $)$ 
(a)

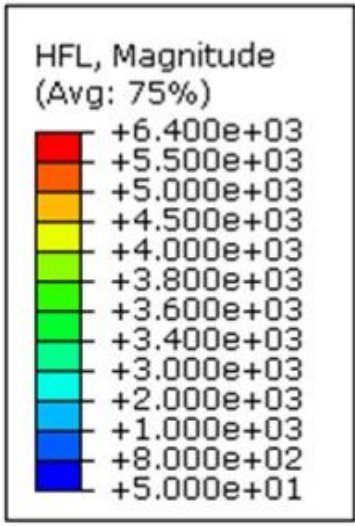

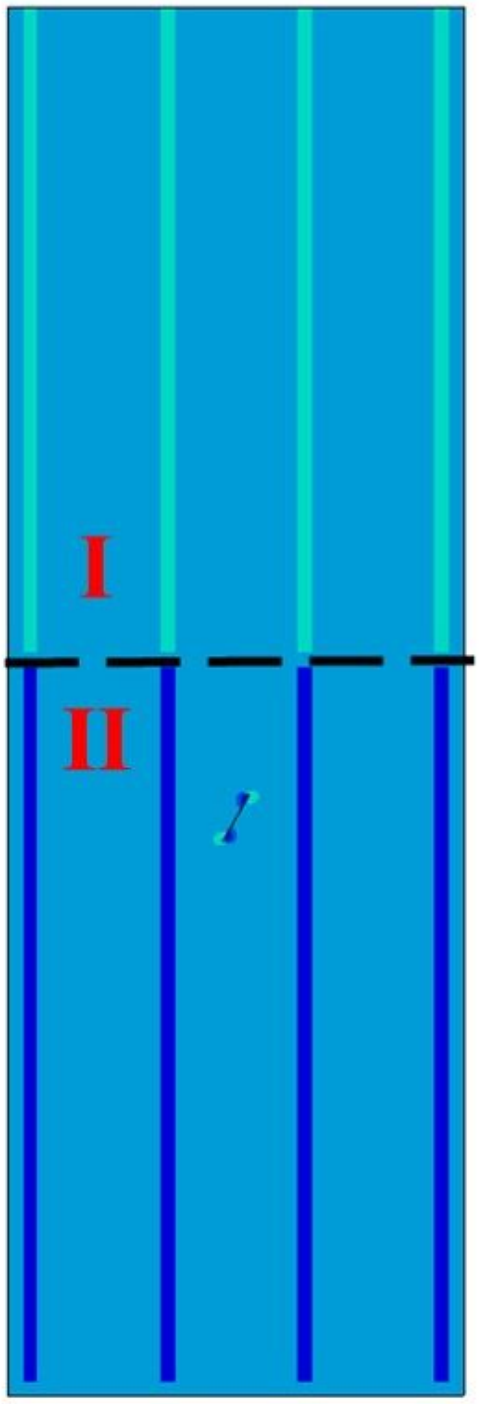

(b)

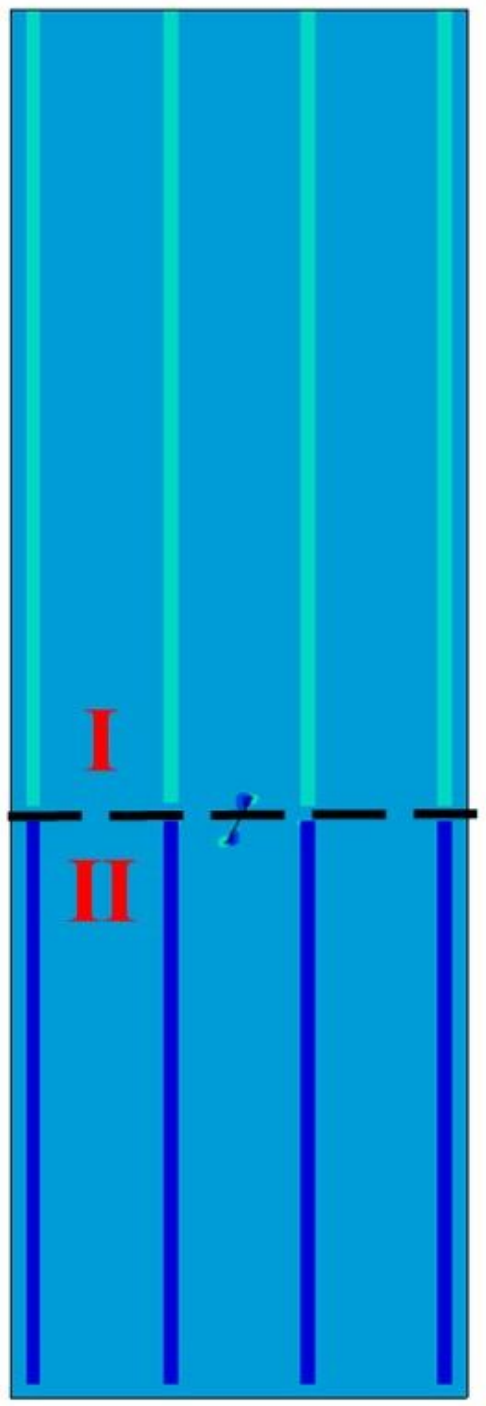

(c)

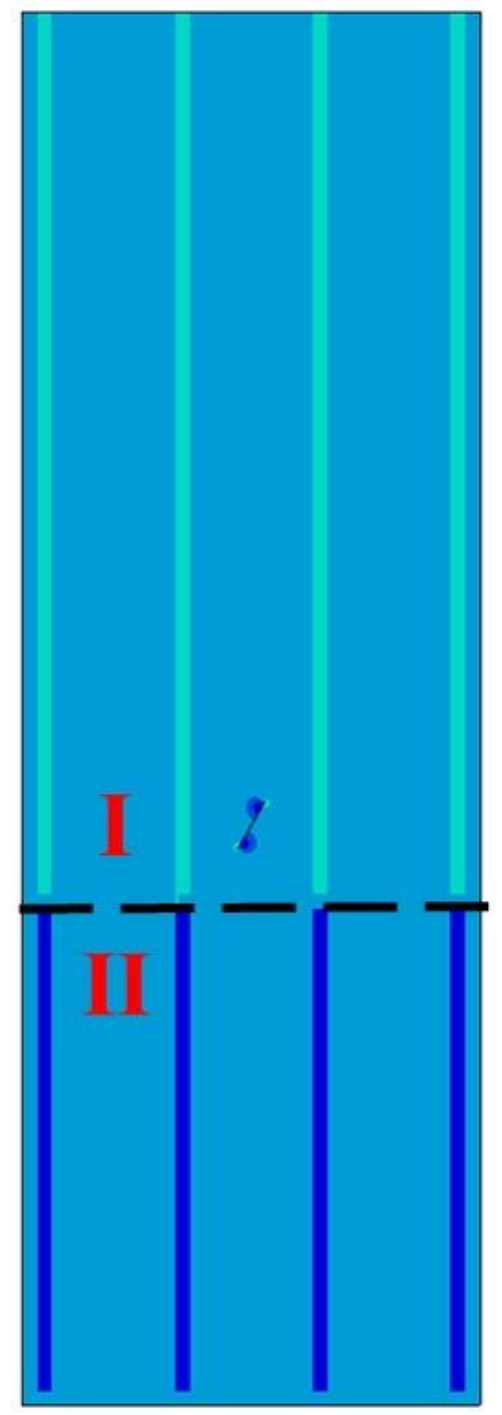

Figure 9

Distribution of Heat flux during holding stage around the YSZ microstructure with the CMAS penetrated zone (I) and CMAS non-penetrated zone (II). (a) $t=9000 \mathrm{~s}(\mathrm{~b}) \mathrm{t}=24000 \mathrm{~s}$ (c) $t=39000 \mathrm{~s}$ (HCRACK $=65 \mu \mathrm{m}$ and ) 
(a)

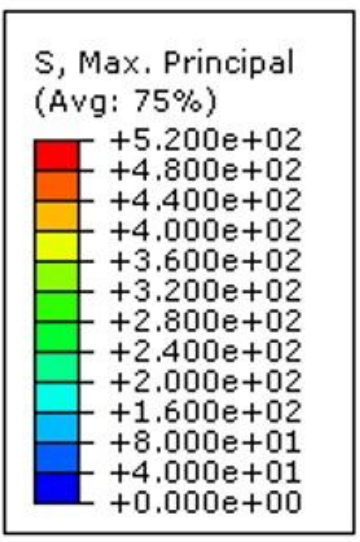

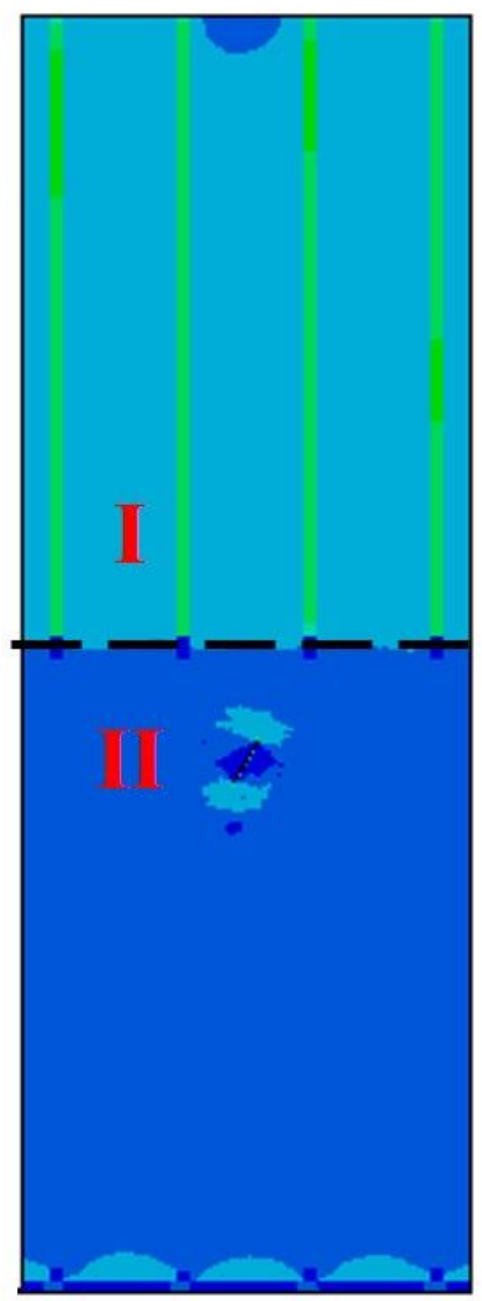

(b)

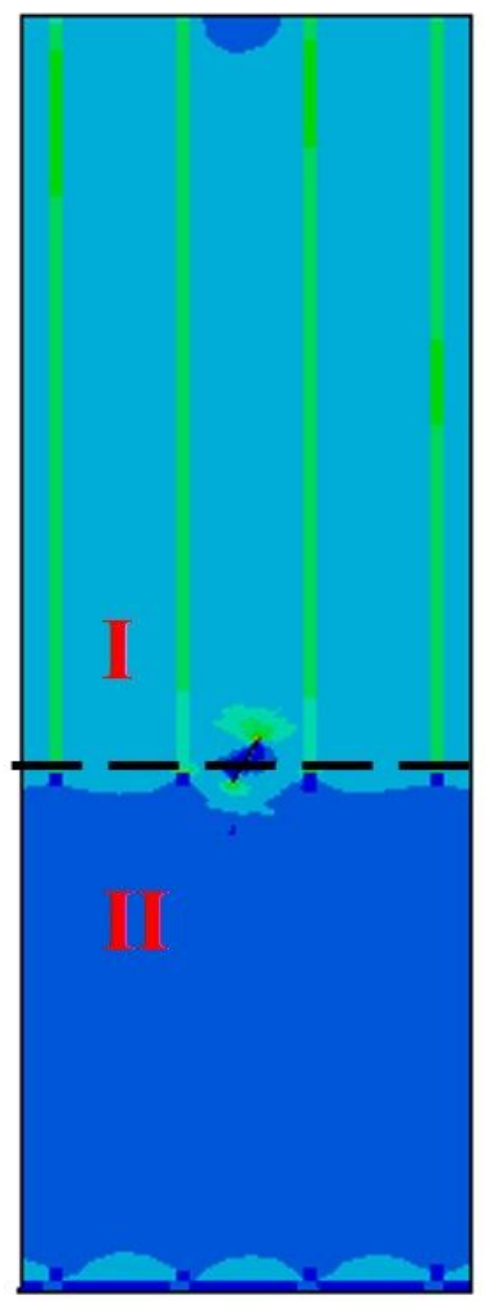

(c)

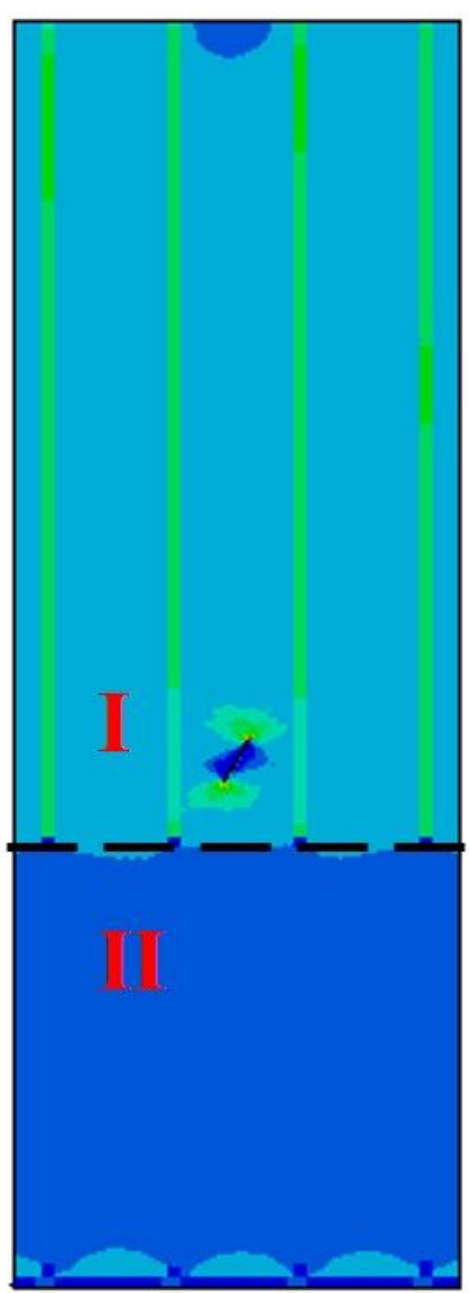

Figure 10

Distribution of maximum principal stress during holding stage around the YSZ microstructure with the CMAS penetrated zone (I) and CMAS non-penetrated zone (II). (a) $t=9000 \mathrm{~s}(\mathrm{~b}) t=24000 \mathrm{~s}(\mathrm{c}) \mathrm{t}=39000 \mathrm{~s}$

(a)

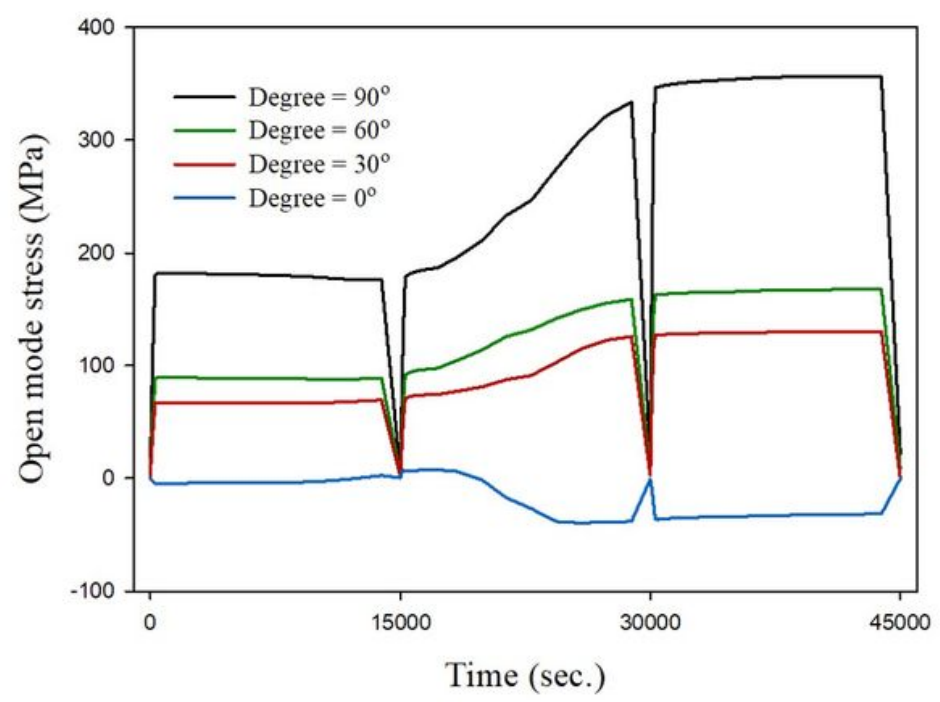

(b)

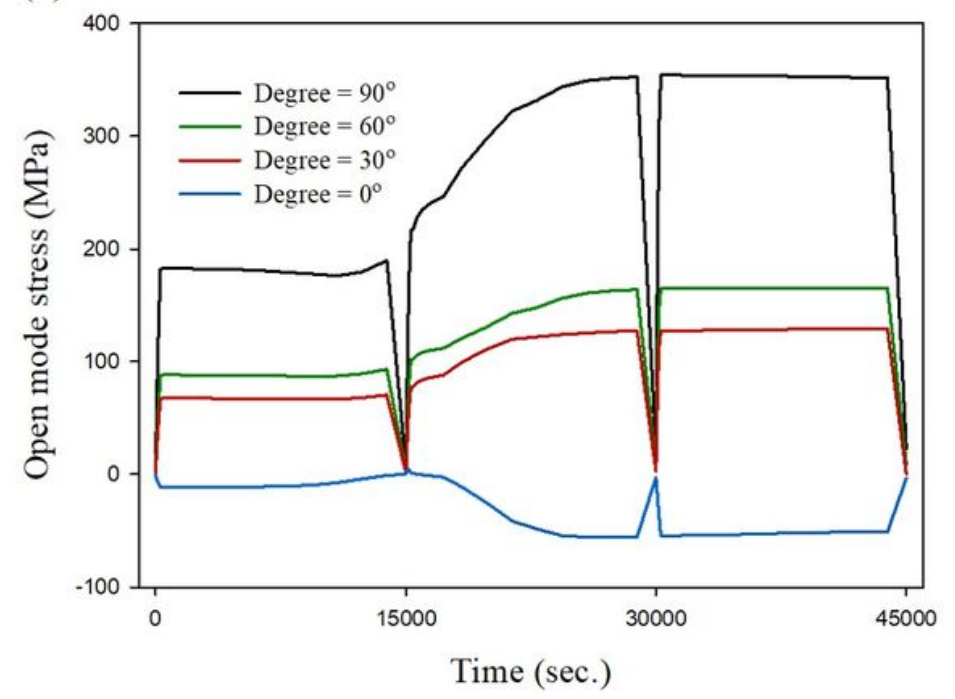


Figure 11

Open-mode stress near the crack tip for different crack inclination angles during dynamic CMAS infiltration: (a) tip-A and (b) tip-B (HCRACK $=60 \mu \mathrm{m}$, aCMAS $=8.5 \times 10-6(\mathrm{C}-1)$, and $\mathrm{KCMAS}=1.78 \mathrm{~W} / \mathrm{mK}$ )

(a)

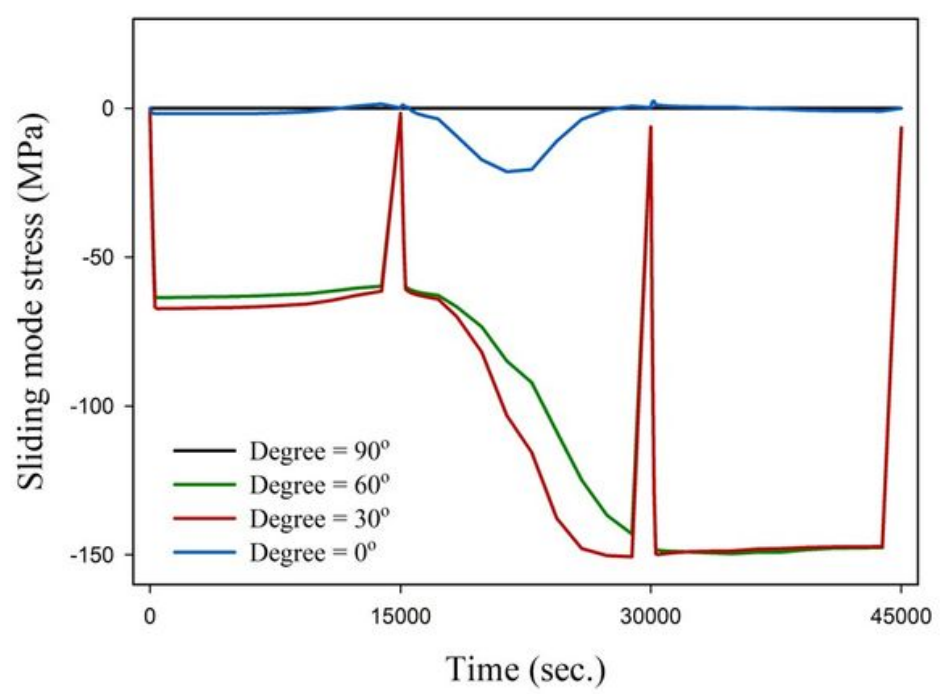

(b)

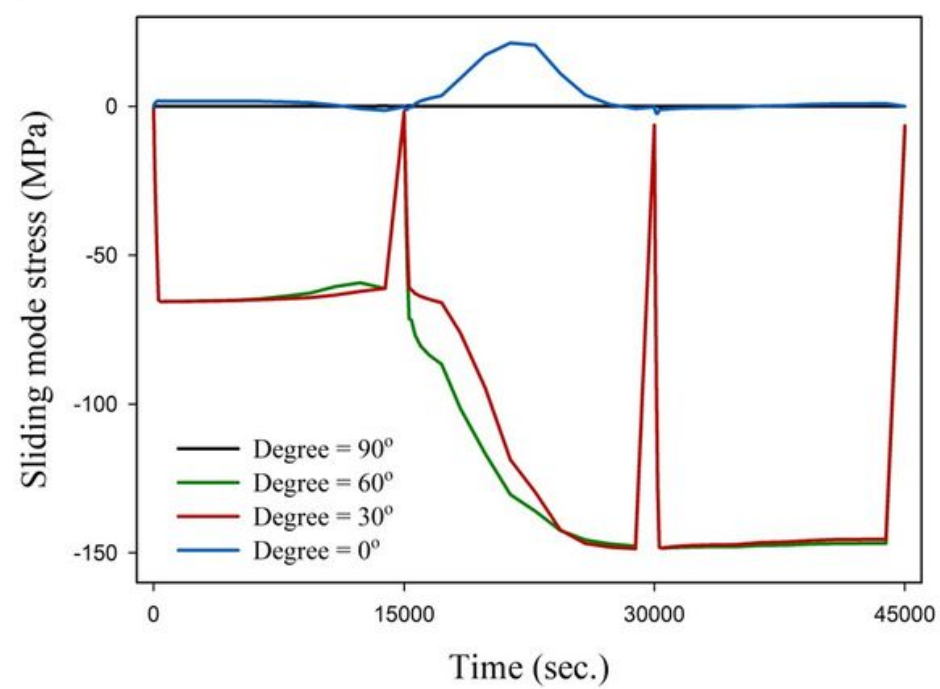

Figure 12

Sliding-mode stress near the crack tip for different crack inclination angles during dynamic CMAS infiltration: (a) tip-A and (b) tip-B

(a)

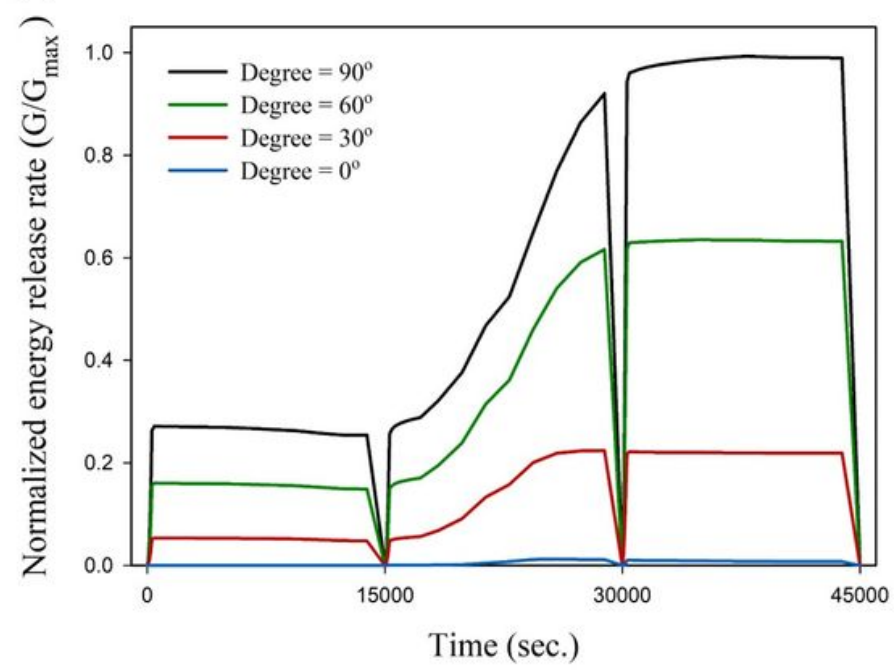

(b)

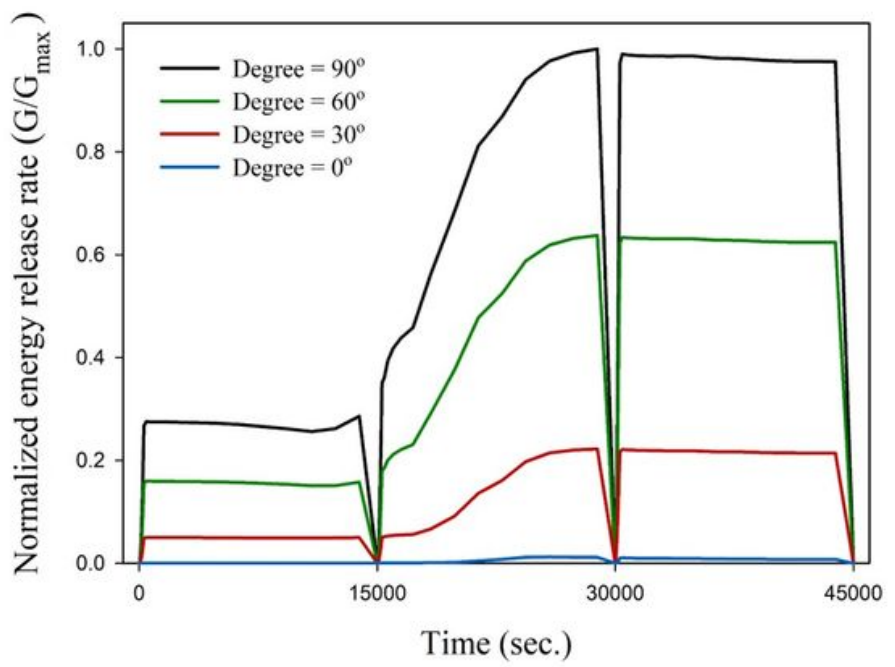

Figure 13

Normalized strain energy release rates for different crack inclination angles during dynamic CMAS infiltration: (a) tip-A and (b) tip-B 
(a)

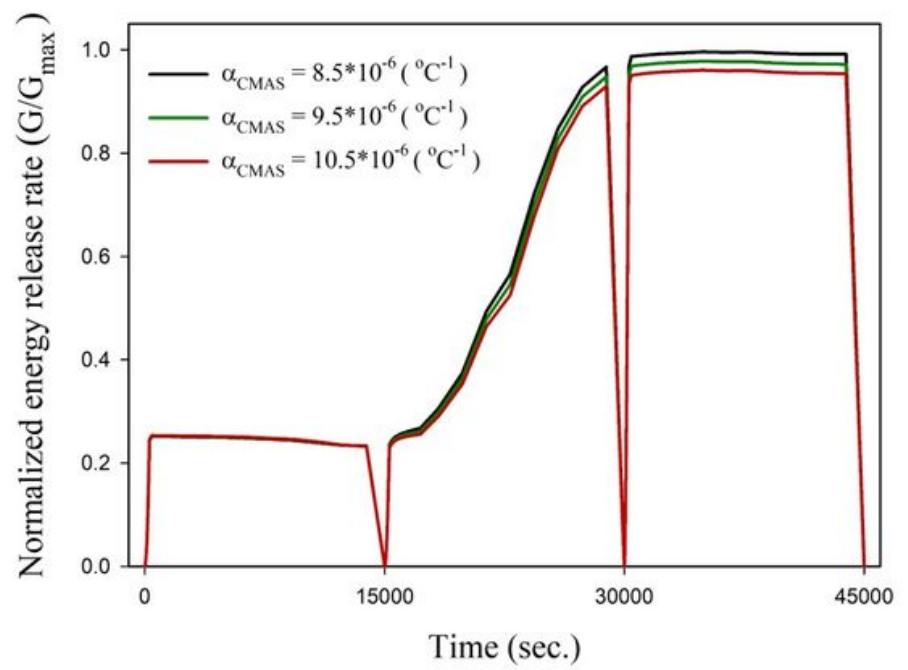

(b)

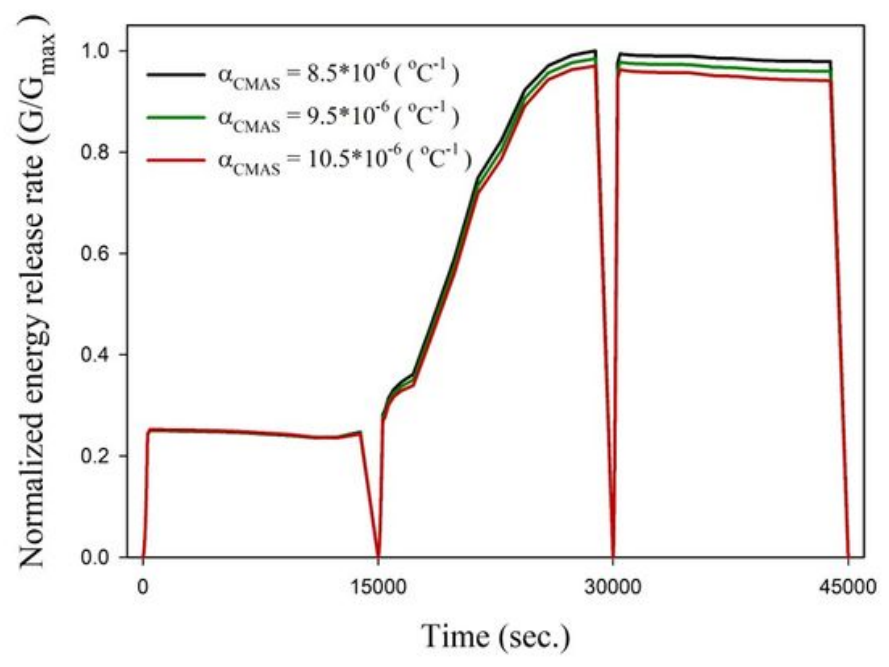

Figure 14

Normalized strain energy release rates for different CMAS thermal expansion coefficients during dynamic CMAS infiltration: (a) tip-A and (b) tip-B

(a)

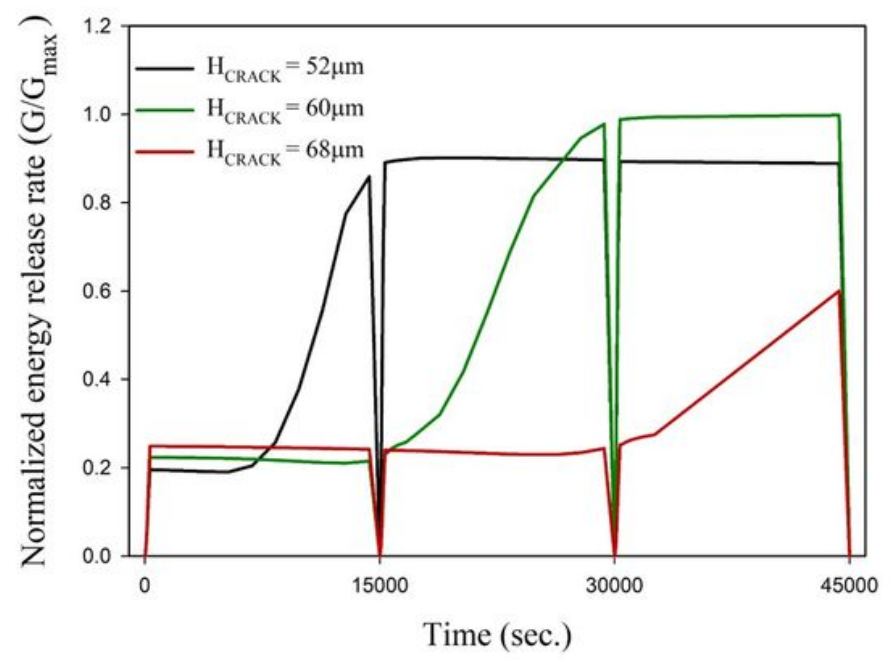

(b)

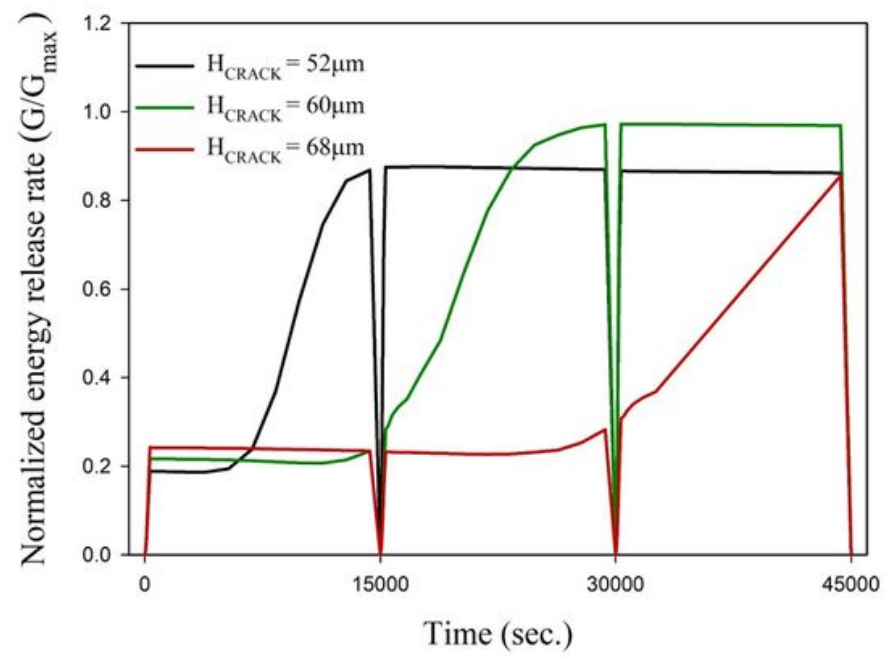

Figure 15

Normalized strain energy release rates for different microcrack heights during CMAS dynamic infiltration:

(a) tip-A and (b) tip-B 
(a)

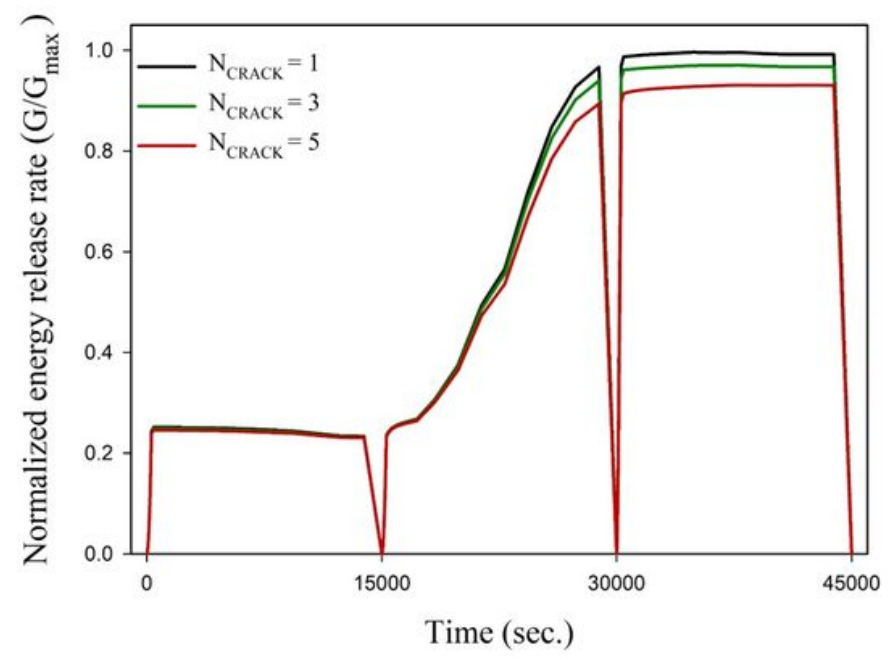

(b)

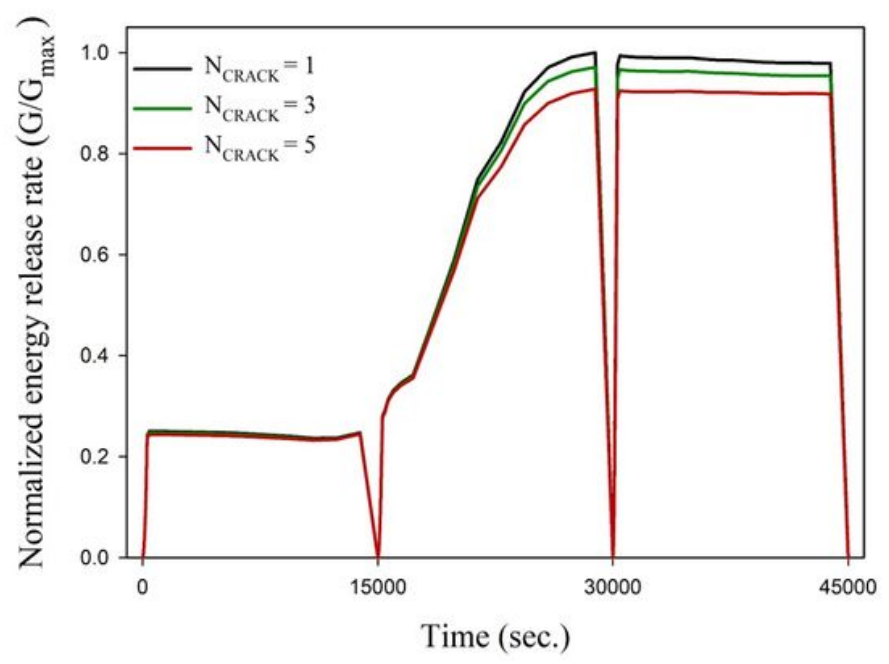

Figure 16

Normalized strain energy release rates for different amounts of microcracks during dynamic CMAS infiltration: (a) tip-A and (b) tip-B

(a)

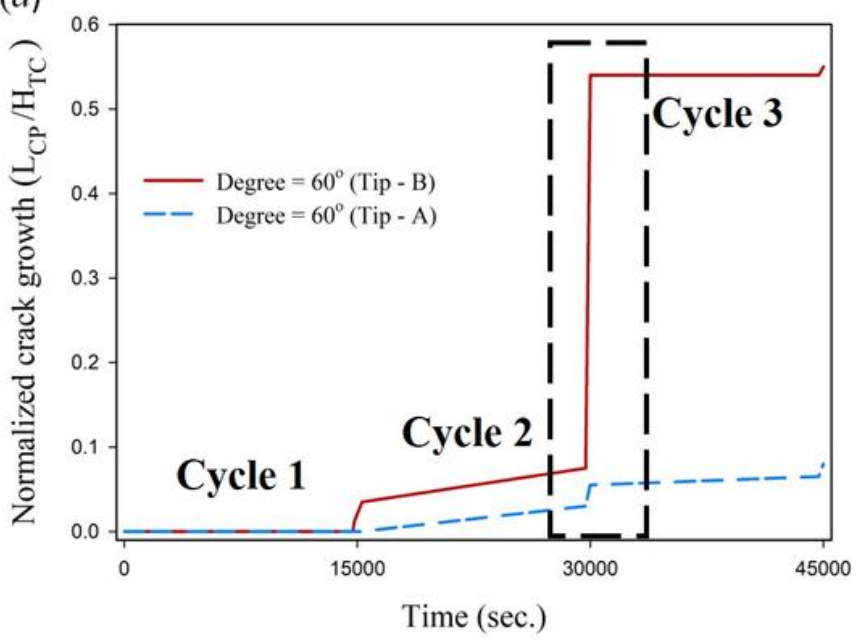

(b)

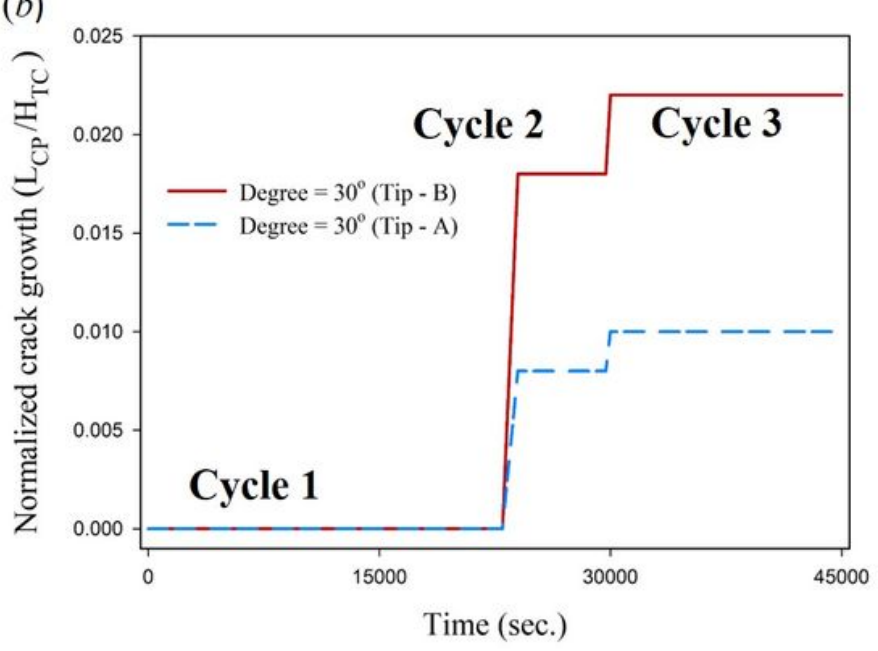

Figure 17

Normalized crack growth for tip-A and tip-B during CMAS infiltration around \#6 YSZ column: (a) inclination angle $=60^{\circ}$ and $(\mathrm{b})$ inclination angle $=30^{\circ}$ 
(a)

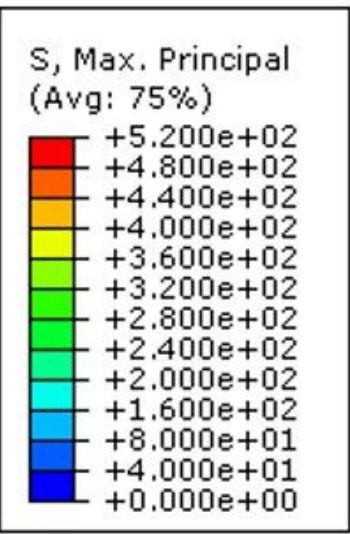

(d)

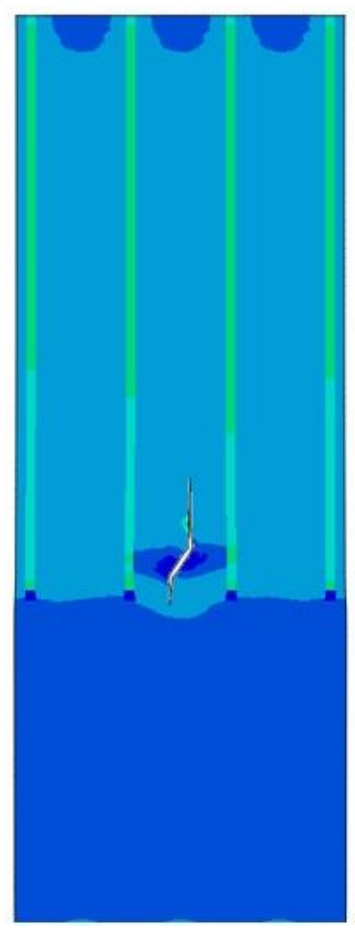

(b)

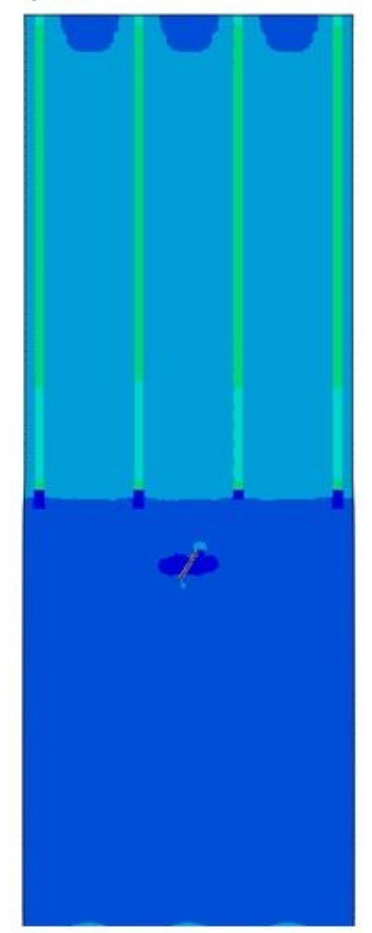

(e)

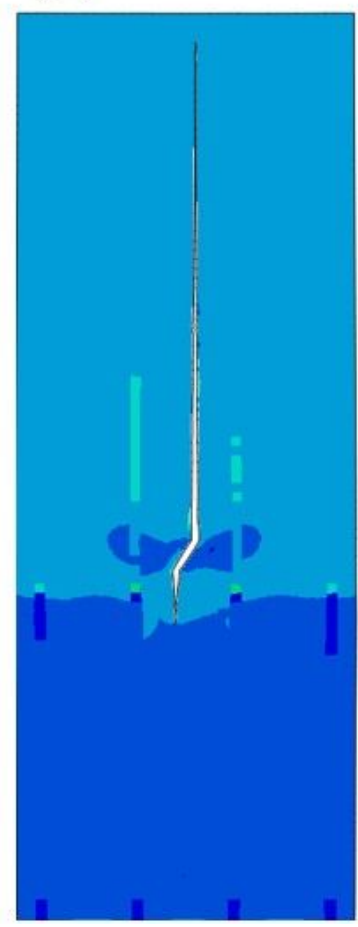

(c)

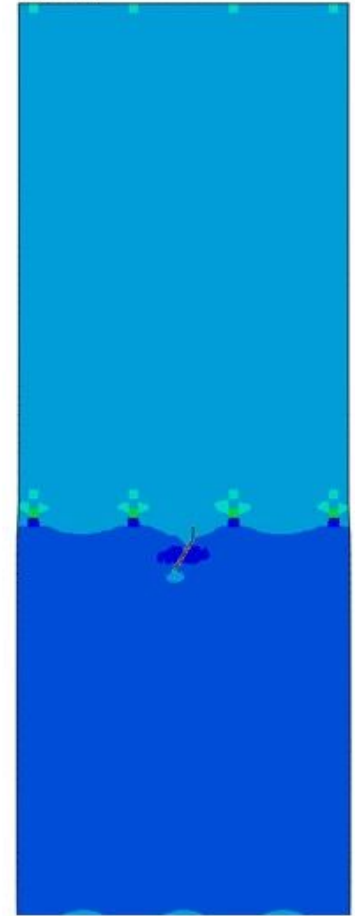

$(f)$

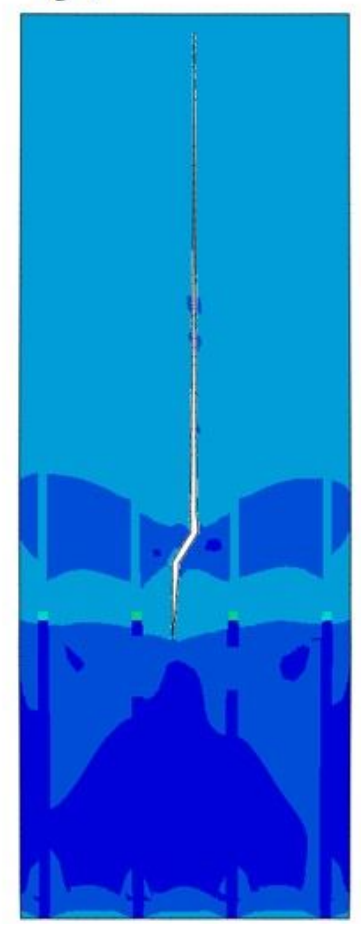

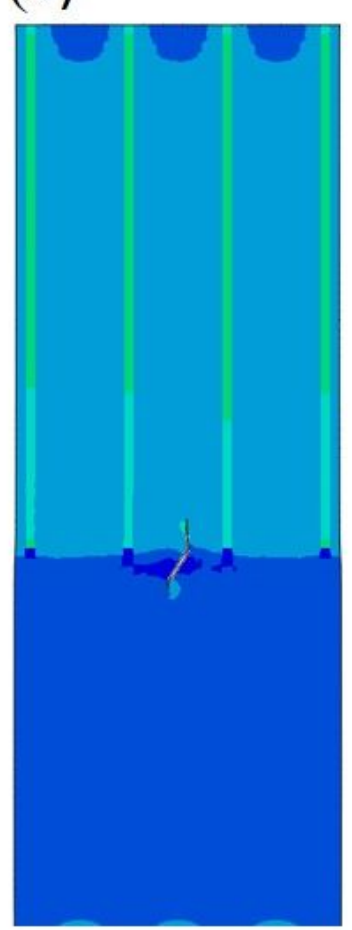

$(g)$

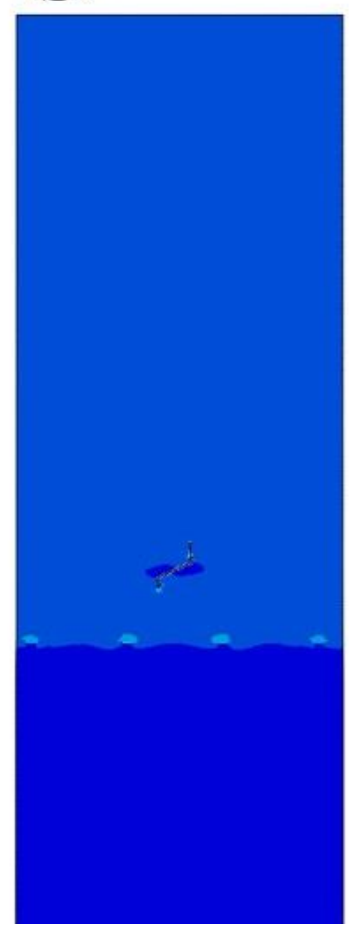

\section{Figure 18}

Distribution of maximum principal stress around the YSZ microstructure of microcrack propagation induced by dynamic CAMS infiltration (HCRACK $=60 \mu \mathrm{m}$, and ) (a) $t=10000 \mathrm{~s}, \theta=60 \_0$ (b) $t=14800 \mathrm{~s}$, $\theta=60 \_0$ (c) $t=18000 s, \theta=60 \_0$ (d) $t=29650 s, \theta=60 \_0$ (e) $t=29900 s, \theta=60 \_0$ (f) $t=44900 s, \theta=60 \_0$ (g) $t=$ 44900s, $\theta=40 \_0$ 


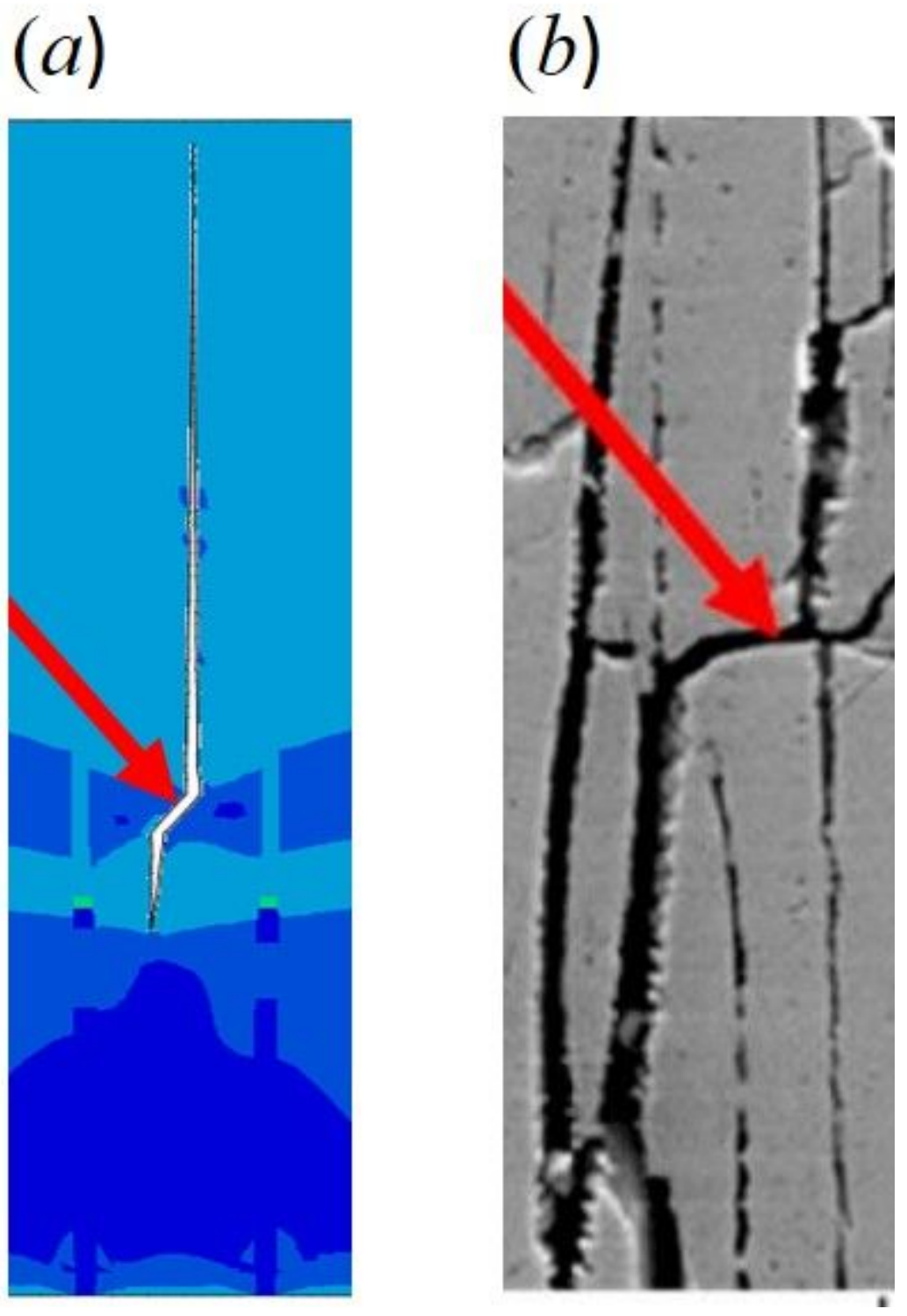

Figure 19

Comparison of failure behavior between (a) finite element method and (b) experimental method [17] 
Heat flux contour Temperature contour
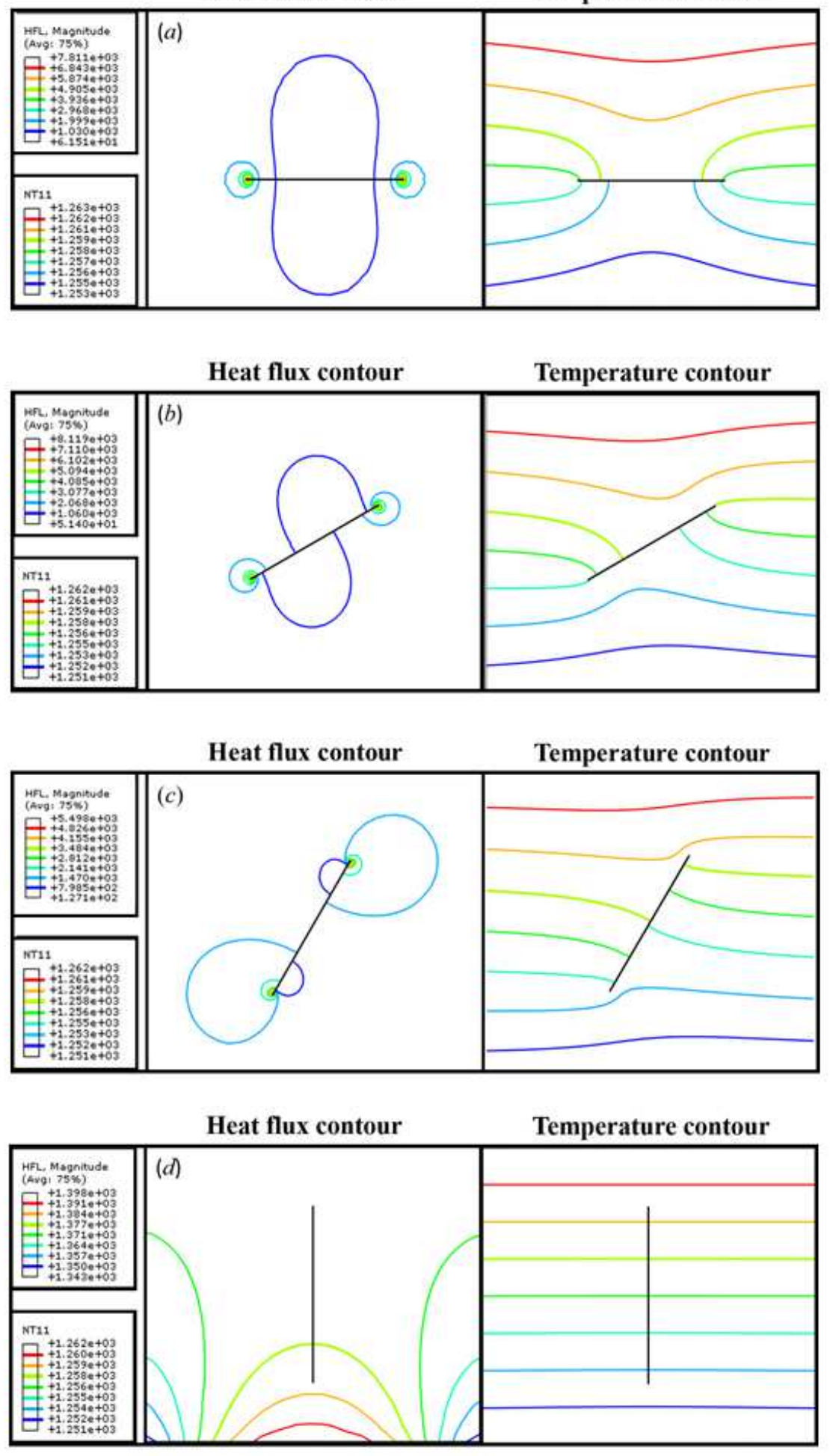

\section{Figure 20}

Heat flux and temperature contours in the TC layer for different crack inclination angles: (a) $0^{\circ}$, (b) $30^{\circ}$, (c) $60^{\circ}$, and (d) $90^{\circ}$ (400s) 